\title{
Bafilomycin A1 activates respiration of neuronal cells via uncoupling associated with flickering depolarization of mitochondria
}

\author{
Alexander V. Zhdanov • Ruslan I. Dmitriev • \\ Dmitri B. Papkovsky
}

Received: 2 April 2010/Revised: 8 July 2010/ Accepted: 6 August 2010/Published online: 6 September 2010

(C) The Author(s) 2010. This article is published with open access at Springerlink.com

\begin{abstract}
Bafilomycin A1 (Baf) induces an elevation of cytosolic $\mathrm{Ca}^{2+}$ and acidification in neuronal cells via inhibition of the V-ATPase. Also, Baf uncouples mitochondria in differentiated PC12 ( $\left.{ }_{d} \mathrm{PC} 12\right),{ }_{\mathrm{d}} \mathrm{SH}-\mathrm{SY} 5 \mathrm{Y}$ cells and cerebellar granule neurons, and markedly elevates their respiration. This respiratory response in ${ }_{\mathrm{d}} \mathrm{PC} 12$ is accompanied by morphological changes in the mitochondria and decreases the mitochondrial $\mathrm{pH}, \mathrm{Ca}^{2+}$ and $\Delta \Psi \mathrm{m}$. The response to $\mathrm{Baf}$ is regulated by cytosolic $\mathrm{Ca}^{2+}$ fluxes from the endoplasmic reticulum. Inhibition of permeability transition pore opening increases the depolarizing effect of Baf on the $\Delta \Psi \mathrm{m}$. Baf induces stochastic flickering of the $\Delta \Psi \mathrm{m}$ with a period of $20 \pm 10 \mathrm{~s}$. Under conditions of suppressed ATP production by glycolysis, oxidative phosphorylation impaired by Baf does not provide cells with sufficient ATP levels. Cells treated with Baf become more susceptible to excitation with $\mathrm{KCl}$. Such mitochondrial uncoupling may play a role in a number of (patho)physiological conditions induced by Baf.
\end{abstract}

Electronic supplementary material The online version of this article (doi:10.1007/s00018-010-0502-8) contains supplementary material, which is available to authorized users.

\footnotetext{
A. V. Zhdanov $(\bowtie) \cdot$ R. I. Dmitriev · D. B. Papkovsky Biochemistry Department, University College Cork, Cavanagh Pharmacy Building, College Road,

Cork, Republic of Ireland

e-mail: a.zhdanov@ucc.ie

R. I. Dmitriev

e-mail: R.Dmitriev@ucc.ie

D. B. Papkovsky

e-mail: d.papkovsky@ucc.ie
}

Keywords Bafilomycin A1 - Mitochondrial uncoupling · Oxygen sensing · Neuronal cells · Calcium · Bioenergetics . Respiration · V-ATPase

\section{Introduction}

Since being described as an inhibitor of vacuolar $\mathrm{H}^{+}$-ATPase (V-ATPase) [1], plecomacrolide bafilomycin A1 (Baf) has become a powerful pharmacological tool in cell physiology research. V-ATPases comprise a family of structurally conserved proteins with multiple functions, which pump protons against the concentration gradient into acidic organelles, and create conditions for protein degradation, receptor-ligand dissociation, and turnover of both neurotransmitters and $\mathrm{Ca}^{2+}[2,3]$. In neuronal cells one of their main functions is to provide the driving force for filling vesicles with neurotransmitters (NT) by the vacuolar $\mathrm{H}^{+} / \mathrm{NT}$ antiporters. Recent study has demonstrated that the V-ATPase is also involved in synaptic vesicle swelling which precedes neurotransmission [4]. As neuronal activity requires frequent NT release and vesicle recharge, V-ATPase consumes a considerable proportion of ATP produced in neurons.

V-ATPase activity is regulated by actin cytoskeleton remodelling, the activity of $\mathrm{Cl}^{-}$channels, PI3K signalling, glucose supply, and the assembly of its subunits [2]. Along with Baf, V-ATPases can be inhibited by concanamycin A (CMA) and other pharmacological compounds [5]. Baf [6] interacts with the V0 subunit $c[7,8]$ and impairs translocation of protons into acidic compartments. Such inhibition has severe implications and leads to lysosome dysfunction, neurotransmission failure, cytosol acidification, impairment of polarized $\mathrm{Ca}^{2+}$ signalling and elevation of cytosolic $\mathrm{Ca}^{2+}[2,9-13]$. The decrease in $\mathrm{pH}$ and 
increase in $\mathrm{Ca}^{2+}$ in the cytosol, in turn, can induce opening of the permeability transition pores (PTP) [14] and cell death. The anticancer effect of Baf is well known and is attributed mainly to the inhibition of autophagy [15] by preventing the fusion of autophagosomes with dysfunctional lysosomes [16, 17], consequently triggering apoptosis [15]. Other mechanisms of cancer inhibition by Baf have also been proposed. Thus, by stabilizing the HIF$1 \alpha$, Baf has been shown to induce the $\mathrm{p} 21^{\mathrm{WAF} 1 / \mathrm{Cip} 1}$-mediated growth arrest in a number of cancer cell lines and to stimulate direct interaction of the V0 subunit $c$ with HIF- $1 \alpha$ [18-20]. Also, both Baf and CMA induce mitochondrial depolarization and apoptosis in leukaemic monocytes by activating NO production [21]. On the other hand, Baf at subnanomolar concentrations has been shown to inhibit chloroquine-induced caspase- 3 activity and apoptosis of the noncancerous cerebellar granule neurons (CGN) [22].

So far, most of the effects of Baf have been attributed to its V-ATPase inhibitory function. Little attention has been paid to its uncoupling effect demonstrated on isolated rat liver mitochondria, which was attributed to its $\mathrm{K}^{+}$ionophore activity [23]. This, however, may be linked to some of the effects of Baf observed in vitro and in vivo, since mitochondrial uncoupling is implicated in cell and organspecific toxicity of many drugs [24].

Considering the multiple targets and signalling pathways described for Baf, we undertook a detailed investigation of its effects on the mitochondrial function and bioenergetic parameters of neuronal cells using differentiated neurosecretory PC12 cells $\left({ }_{d} \mathrm{PC} 12\right)$ as a model. Derived from rat adrenal phaeochromocytoma, ${ }_{\mathrm{d}} \mathrm{PC} 12$ cells demonstrate gene expression profiles, NT release and other features typical of neuronal cells $[25,26]$, while both oxidative phosphorylation (OxPhos) and glycolysis serve as effective suppliers of cellular ATP $[27,28]$. An intracellular oxygen $\left({ }_{i} \mathrm{O}_{2}\right)$ sensing technique, which allows real-time monitoring of $\mathrm{O}_{2}$ levels in the monolayer of cells, both at rest and upon stimulation $[28,29]$, was used to study the metabolic effects of Baf on PC12 cells. The results were correlated with the other key metabolic markers and parameters of cellular function. The effects found in ${ }_{d} \mathrm{PC} 12$ cells were subsequently confirmed in differentiated neuroblastoma SH-SY5Y cells and CGN from rat brain.

\section{Materials and methods}

\section{Materials}

PC12 and SH-SY5Y cells were obtained from the European and American collections of cell cultures. The oxygensensitive probe MitoXpress and extracellular acidification probe $\mathrm{pH}$-Xtra were from Luxcel Biosciences (Cork,
Republic of Ireland). Bafilomycin A, CMA, nerve growth factor (NGF), collagen IV, 2',7'-bis(2-carboxyethyl)-5(6)carboxyfluorescein (BCECF), carbonyl cyanide 4-(trifluoromethoxy) phenylhydrazone (FCCP), valinomycin, nigericin and other reagents were from Sigma-Aldrich. Endo-Porter was from Gene Tools, LLC (Philomath, OR). Lipofectamine 2000, OptiMEM I, Fluo-4 AM, bis-(1,3-diethylthiobarbituric acid) trimethine oxonol $\left(\operatorname{DiSBAC}_{2}(3)\right)$, tetramethyl rhodamine methyl ester (TMRM), 5, 5',6,6 $6^{\prime}$-tetrachloro-1, $1^{\prime}, 3,3^{\prime}$-tetraethylbenzimidazolylcarbocyanine iodide (JC-1), Hoechst 33342, 5-carboxy-2',7'-dichlorodihydrofluorescein diacetate, diAM (carboxy- $\mathrm{H}_{2}$ DCFDA) and Image-iT LIVE reactive oxygen species (ROS) detection kit were from Invitrogen Life Technologies (Carlsbad, CA and Dun Laoghaire, Republic of Ireland). Camptothecin, 2,5-di-t-butyl-1,4-benzohydroquinone (BHQ) and 7-chloro5-(2-chlorophenyl)-1,5-dihydro-4,1-benzotiazepin-2(3H)one (CGP37157) were from Tocris (Bristol, UK). Plasticware was from Sarstedt (Wexford, Republic of Ireland), MatTek (Ashland, MA) and Greiner Bio One (Frickenhausen, Germany). The peptide caloxin 1C2 (TAWSEVLDLLRRGGGSK-amide) was from GenScript (Piscataway, NJ). The mitochondria-targeted version of GFP-tagged $\mathrm{Ca}^{2+}$ sensor Case12, mito Case12 [30-32] was from Evrogen JSC (Moscow, Russia). The GFP-based plasmid encoding the mitochondrial $\mathrm{pH}$ sensor mtAlpHi [33] was kindly provided by Prof. Tullio Pozzan (University of Padua, Italy). Antibodies were: polyclonal anti-LC3A/B from Cell Signaling Technology (Danvers, MA), rabbit monoclonal anti-Smac/DIABLO from Novus Biologicals (Littleton, CO), mouse monoclonal anti-tubulin from Sigma, goat polyclonal anti-rabbit and anti-mouse IRDye $800 \mathrm{CW}$ from LI-COR Biosciences (Lincoln, NE), donkey anti-rabbit Cy3-conjugated from Jackson ImmunoResearch Laboratory (West Grove, PA).

\section{Cell culture}

PC12 cells were cultured in RPMI 1640 medium supplemented with $2 \mathrm{mM}$ L-glutamine, $10 \%$ horse serum (HS), $5 \%$ fetal bovine serum (FBS), $100 \mathrm{U} / \mathrm{ml}$ penicillin and $100 \mu \mathrm{g} / \mathrm{ml}$ streptomycin (P/S) in an atmosphere containing $5 \% \mathrm{CO}_{2}$. For the $\mathrm{O}_{2}$ and ATP measurements, the cells were seeded at $5 \times 10^{4}$ cells/well into 96-well plates (Sarstedt) coated with $0.01 \%$ collagen IV, and differentiated for 3-5 days in RPMI supplemented with $1 \% \mathrm{HS}, \mathrm{P} / \mathrm{S}, 100 \mathrm{ng} / \mathrm{ml}$ NGF. For live cell imaging, PC12 cells were differentiated on glass bottom mini-dishes (MatTek) coated with a mixture of collagen IV $(0.007 \%)$ and poly-D-lysine $(0.003 \%)$.

SH-SY5Y cells were cultured in DMEM supplemented with $10 \%$ FBS, $2 \mathrm{mM}$ L-glutamine and P/S and differentiated, as described previously [34]. Briefly, the cells were seeded at $6 \times 10^{4}$ cells/well in a 96-well plate coated with 
collagen IV, and at $3 \times 10^{4}$ cells/well in collagen IV/polyD-lysine-coated glass-bottom MatTek mini-dishes [30]. Then the medium was changed to DMEM supplemented with $10 \%$ FBS and $10 \mu \mathrm{M}$ retinoic acid, and the cells were further incubated for 5 days. After that, the medium was changed to DMEM containing $50 \mathrm{ng} / \mathrm{ml}$ brain-derived neurotropic factor (BDNF), and differentiation was continued for 7 days before the experiments.

CGN from 7-day-old rats were prepared, as described previously [35], seeded at $2 \times 10^{5}$ cells/well and maintained in culture in the presence of $10 \mu \mathrm{M}$ cytosine arabinoside for 7 days prior to use.

Preparation of the cells and loading with probes

For the ${ }_{i} \mathrm{O}_{2}$ assay, ${ }_{d} \mathrm{PC} 12$ cells and CGN prepared in 96-well plates were loaded by incubating them for $28 \mathrm{~h}$ in regular medium containing $1.2 \mu \mathrm{M}$ MitoXpress probe and $6 \mu \mathrm{M}$ Endo-Porter transfection reagent, as described previously [28]. ${ }_{\mathrm{d}} \mathrm{SH}-\mathrm{SY} 5 \mathrm{Y}$ cells, which are poorly loaded with the MitoXpress probe, were loaded with the cellpenetrating probe PtCPTE-CFR9 [36] by incubating them with $10 \mu \mathrm{M}$ probe in DMEM/BDNF for $16 \mathrm{~h}$. After loading, the cells were washed with fresh medium three times and used for $\mathrm{O}_{2}$ measurements.

${ }_{\mathrm{d}} \mathrm{PC} 12$ and ${ }_{\mathrm{d}} \mathrm{SH}-\mathrm{SY} 5 \mathrm{Y}$ cells were transfected with mito Case 12 and mtAlpHi plasmids using lipofectamine and OptiMEM I, as per the manufacturer's procedure. The cells were loaded with the following fluorescent indicators in OptiMEM I: $20 \mathrm{nM}$ TMRM (mitochondrial membrane potential, $\Delta \Psi \mathrm{m}$ ), $2.5 \mu \mathrm{M}$ Fluo-4 $\mathrm{AM}$ (cytosolic $\mathrm{Ca}^{2+}$ ), $2.5 \mu \mathrm{M}$ JC-1 $(\Delta \Psi \mathrm{m}), 1 \mu \mathrm{M} \operatorname{DiSBAC}_{2}(3)$ (plasma membrane potential, $\Delta \Psi \mathrm{p}$ ) and $2.5 \mu \mathrm{M}$ BCECF AM (cytosolic $\mathrm{pH}$ ) for $30 \mathrm{~min}, 1 \mu \mathrm{M}$ Hoechst 33342 (nuclear counterstain) for $5 \mathrm{~min}$, and $10 \mu \mathrm{M}$ carboxy- $\mathrm{H}_{2}$ DCFDA (ROS probe) for $45 \mathrm{~min}$. All AM probes were de-esterified for 15 min prior to each experiment. During the measurements, TMRM and $\operatorname{DiSBAC}_{2}(3)$ probes were maintained in solution at $20 \mathrm{nM}$ and $0.25 \mu \mathrm{M}$, respectively. In the majority of the experiments the probes were used individually. Probe combinations were used only when their spectral, spatial and functional characteristics allowed simultaneous loading and measurement. Each spectral signal was acquired in sequential laser mode with emission gates adjusted to avoid overlaps.

\section{Experimental conditions}

The experiments with ${ }_{\mathrm{d}} \mathrm{PC} 12$ cells were carried out in the presence of NGF in serum-free DMEM buffered with $25 \mathrm{mM}$ HEPES, $\mathrm{pH} 7.4\left(\mathrm{O}_{2}\right.$ assays $)$ and in OPTIMEM I with additional $\mathrm{Ca}^{2+}$ at $1 \mathrm{mM}$ (imaging experiments). The experiments with ${ }_{\mathrm{d}} \mathrm{SH}-\mathrm{SY} 5 \mathrm{Y}$ cells were performed in
DMEM buffered with $25 \mathrm{mM}$ HEPES, pH 7.4, and supplemented with BDNF. For both cell lines, most of the experiments were carried out in medium supplemented with $10 \mathrm{mM}$ glucose [glucose (+) condition]. To inhibit the glycolytic pathway of ATP generation [37], the cells were incubated in serum and glucose-free medium, containing $10 \mathrm{mM}$ galactose and $1 \mathrm{mM}$ pyruvate [galactose $(+)$ condition] for $3 \mathrm{~h}$ prior to the measurements. The measurements on CGN were carried out in buffer containing $120 \mathrm{mM} \mathrm{NaCl}, 3.5 \mathrm{mM} \mathrm{KCl}, 0.4 \mathrm{mM} \mathrm{KH} \mathrm{KO}_{4}$, $20 \mathrm{mM}$ HEPES, $5 \mathrm{mM} \mathrm{NaHCO}, 1.2 \mathrm{mM} \mathrm{Na} \mathrm{SO}_{4}$, $1.2 \mathrm{mM} \mathrm{CaCl}_{2}, 1.2 \mathrm{mM} \mathrm{MgCl}_{2}$, and $15 \mathrm{mM}$ glucose, $\mathrm{pH}$ 7.4, as described previously [38]. Conditions of treatment with various effectors (dose, timing and media) are described in the "Results"

Intracellular $\mathrm{O}_{2}$ sensing assay

Typically, a standard 96-well plate containing 24 samples of ${ }_{d} \mathrm{PC} 12$ and ${ }_{\mathrm{d}} \mathrm{SH}-\mathrm{SY} 5 \mathrm{Y}$ cells preloaded with the $\mathrm{O}_{2}$ probe in $90 \mu \mathrm{l}$ of air-saturated medium was measured on a timeresolved fluorescence (TR-F) plate reader (Victor 2; PerkinElmer Life Science) at $37^{\circ} \mathrm{C}$ using $340 \mathrm{~nm}$ excitation and $642 \mathrm{~nm}$ emission filters. Each sample well was measured repeatedly every $1.3-6 \mathrm{~min}$ by taking two intensity readings at delay times of 30 and $70 \mu$ s and a gate time of $100 \mu \mathrm{s}$ [29]. The plate was initially monitored for 10-20 min to allow $\mathrm{O}_{2}$ and temperature equilibrium to be reached and to obtain baseline signals. The plate was then quickly withdrawn from the reader, compounds were added to the cells ( $10 \mu \mathrm{l}$ of $10 \times$ stock solution) and monitoring was resumed. Measured TR-F intensity signals for each sample well were converted into phosphorescence life-time $(\tau)$ values and plotted as time profiles. These profiles were related to ${ }_{i} \mathrm{O}_{2}$ concentration $(\mu \mathrm{M})$ according to the following equation: $\left[\mathrm{O}_{2}\right]=-0.0027 \tau^{3}+0.5649 \tau^{2}-$ $40.104 \tau+972.23$. This equation was obtained from the calibration of the $\mathrm{O}_{2}$ probe [39], performed in a hypoxia chamber (Coy Scientific) equilibrated at given $\mathrm{O}_{2}$ saturation levels (0-20.9\% of air saturation). Normoxic $20.91 \%$ $\mathrm{O}_{2}$ in the air roughly corresponded to $200 \mu \mathrm{M} \mathrm{O} \mathrm{O}_{2}$ in solution at $+37^{\circ} \mathrm{C}$ [40]. Control samples were incorporated as appropriate.

Measurement of $\Delta \Psi_{\mathrm{m}}, \Delta \Psi_{\mathrm{p}}$, intracellular $\mathrm{Ca}^{2+}, \mathrm{pH}$, ATP and ROS

Intracellular $\mathrm{pH}$, cytosolic and mitochondrial $\mathrm{Ca}^{2+}, \Delta \Psi_{\mathrm{m}}$, $\Delta \Psi_{\mathrm{p}}$ and ROS production were measured using an Olympus FV1000 confocal laser scanning microscope under controlled conditions of $\mathrm{CO}_{2}$, humidity and temperature. The BCECF, Fluo-4, carboxy- $\mathrm{H}_{2}$ DCFDA (Image-iT LIVE ROS detection kit), mito Case12 and mtAlpHi probes were excited 
at $488 \mathrm{~nm}(0.5,5,15,1.5$ and $10 \%$ of laser power, respectively) with emission collected at $500-550 \mathrm{~nm}$. TMRM and DiSBAC 2 (3) were excited at $543 \mathrm{~nm}$ (1.5 and $1 \%$ laser power) collecting the emission with a 555-600 nm filter. JC-1 probe was excited at 488 and $543 \mathrm{~nm} \mathrm{(1} \mathrm{and} \mathrm{5 \%}$ laser power) with emission collected at 500-540 and 555-600 nm. Hoechst 33342 was excited at $405 \mathrm{~nm} \mathrm{(3 \%}$ laser power) with emission collected at $440-480 \mathrm{~nm}$. In all the experiments fluorescent and differential interference contrast (DIC) images were acquired with a $60 \times$ oil immersion objective in two planes using a $0.5 \mu \mathrm{M}$ step and $5-120 \mathrm{~s}$ intervals. The resulting $z$-stacked images were analysed using a FV1000 viewer (Olympus), Adobe Photoshop and Illustrator software. Mitochondria within neurites (rather than cell bodies) were used in the analyses of the TMRM fluctuations, because in this case movements of the mitochondria are constrained and they are readily observable. Cellular ATP was measured using a CellTiterGlo assay kit (Promega, Madison) on a white 96-well plate (Greiner Bio One). ROS levels were measured using a carboxy- $\mathrm{H}_{2} \mathrm{DCFDA}$ probe and fluorescence activated cell sorter (FACS) analysis (Becton-Dickinson, $\mathrm{NJ}$ ).

\section{Extracellular acidification assay}

The rate of extracellular acidification was monitored as described previously [41]. PC12 cells were differentiated for 4-5 days under standard $\mathrm{CO}_{2}$ conditions, then the medium was replaced with unbuffered DMEM, supplemented with $1 \mathrm{mM}$ sodium pyruvate and either $10 \mathrm{mM}$ glucose or $10 \mathrm{mM}$ galactose, $\mathrm{pH} 7.4$ ( $\mathrm{pH}$ buffer). Cells were maintained in a $\mathrm{CO}_{2}$-free incubator at $37^{\circ} \mathrm{C}$ for $3 \mathrm{~h}$ prior to measurement and then the medium was replaced with $100 \mu \mathrm{l}$ of fresh medium containing $1 \mu \mathrm{M}$ of $\mathrm{pH}-\mathrm{X}$ tra probe and the stimulants. The plate was then measured kinetically on the Victor 2 plate reader at $37^{\circ} \mathrm{C}$ for a minimum of $30 \mathrm{~min}$ in the TR-F mode using a europium filter set $(340 \pm 35 \mathrm{~nm}$ excitation and $615 \pm 8.5 \mathrm{~nm}$ emission). Two TR-F intensity signals were measured at delay times of 100 and $300 \mu$ s and a measurement window of $30 \mu \mathrm{s}$. The readings were converted into life-time values $\tau=\left(t_{1}-t_{2}\right) / \ln \left(F_{1} / F_{2}\right)$, where $\tau$ is the probe fluorescence life-time, $t_{1}$, and $t_{2}$ are the two delay times, and $F_{1}$ and $F_{2}$ are the corresponding TR-F intensity signals; $\tau$ was converted into $\mathrm{pH}$ and $\mathrm{H}^{+}$values [41].

Detection of autophagic flux and apoptosis

The level of autophagy was assessed by LC3 degradation using Western blot analysis [42]. Briefly, ${ }_{\mathrm{d}} \mathrm{PC} 12$ cells were incubated under normal or starving (HBSS supplemented with $100 \mathrm{ng} / \mathrm{ml} \mathrm{NGF)} \mathrm{conditions} \mathrm{for} 2 \mathrm{~h}$ and then treated with $0.25 \mu \mathrm{M}$ Baf or CMA under starving conditions for $4 \mathrm{~h}$.
Whole-cell lysate proteins were separated with gradient gel electrophoresis, transferred onto a PVDF membrane and probed with anti-LC3A/B and IRDye $800 \mathrm{CW}$ antibodies. Immunoblotting results were analysed using the Odyssey infrared imaging system (LI-COR Biosciences).

The level of apoptosis was measured by Smac/DIABLO translocation (immunofluorescence), and caspase-3 activation (fluorescent plate reader). Immunofluorescence analysis was performed as described previously [43]. Briefly, cells treated for 2-4 h with Baf, CMA or $5 \mu \mathrm{M}$ camptothecin were fixed with $3.7 \%$ PFA, permeabilized with $0.25 \%$ TX100, incubated with anti-Smac and stained with Cy3-conjugated secondary antibodies. Results were analysed by confocal microscopy.

Caspase-3 activation was determined using a kit from Cayman Chemicals (Ann Arbor, MI) according to the manufacturer's protocol. Briefly, ${ }_{d} \mathrm{PC} 12$ cells were incubated with drugs as described in the "Results", washed in assay buffer and lysed. After addition of the enzyme substrate, caspase-3 activity was measured in a 96-well plate using the Victor 2 reader at $485 \mathrm{~nm} / 535 \mathrm{~nm}$ (fluorescence excitation/emission).

\section{Statistics}

The data were evaluated for the significance of differences using the two-tailed Student $t$-test. The 0.01 level of confidence was accepted as statistically significant. Plate reader data are presented as average values \pm standard deviation for six to eight repeated wells (error bars on the plots). Imaging data are presented as the averages from five to ten individual cells. All the experiments were repeated three to five times to ensure consistency of the results.

\section{Results}

Bafilomycin A1 activates the respiration and induces sustained deoxygenation of neural cells

Although uncoupling of isolated mitochondria by Baf has been described [23], its effects on cell respiration have not been investigated. Using the intracellular $\mathrm{O}_{2}$ sensing technique [29], we found that exposure of ${ }_{\mathrm{d}} \mathrm{PC} 12$ cells to $0.25 \mu \mathrm{M}$ Baf gradually decreased the oxygenation of the cell monolayer from $140-160 \mu \mathrm{M}$ down to $80 \pm 5 \mu \mathrm{M} \mathrm{O}_{2}$ (Fig. 1a) due to increased respiration. Maximal respiration was achieved in 50-100 min, and then it gradually decreased but still remained elevated after $>5 \mathrm{~h}$. The effect was dose-dependent, becoming significant at $50 \mathrm{nM}$ and reaching a maximum at $0.5-0.8 \mu \mathrm{M}$ Baf after $45 \mathrm{~min}$ of treatment (Fig. 1b). In the presence of mitochondrial complex III inhibitor antimycin A the effect was abolished 

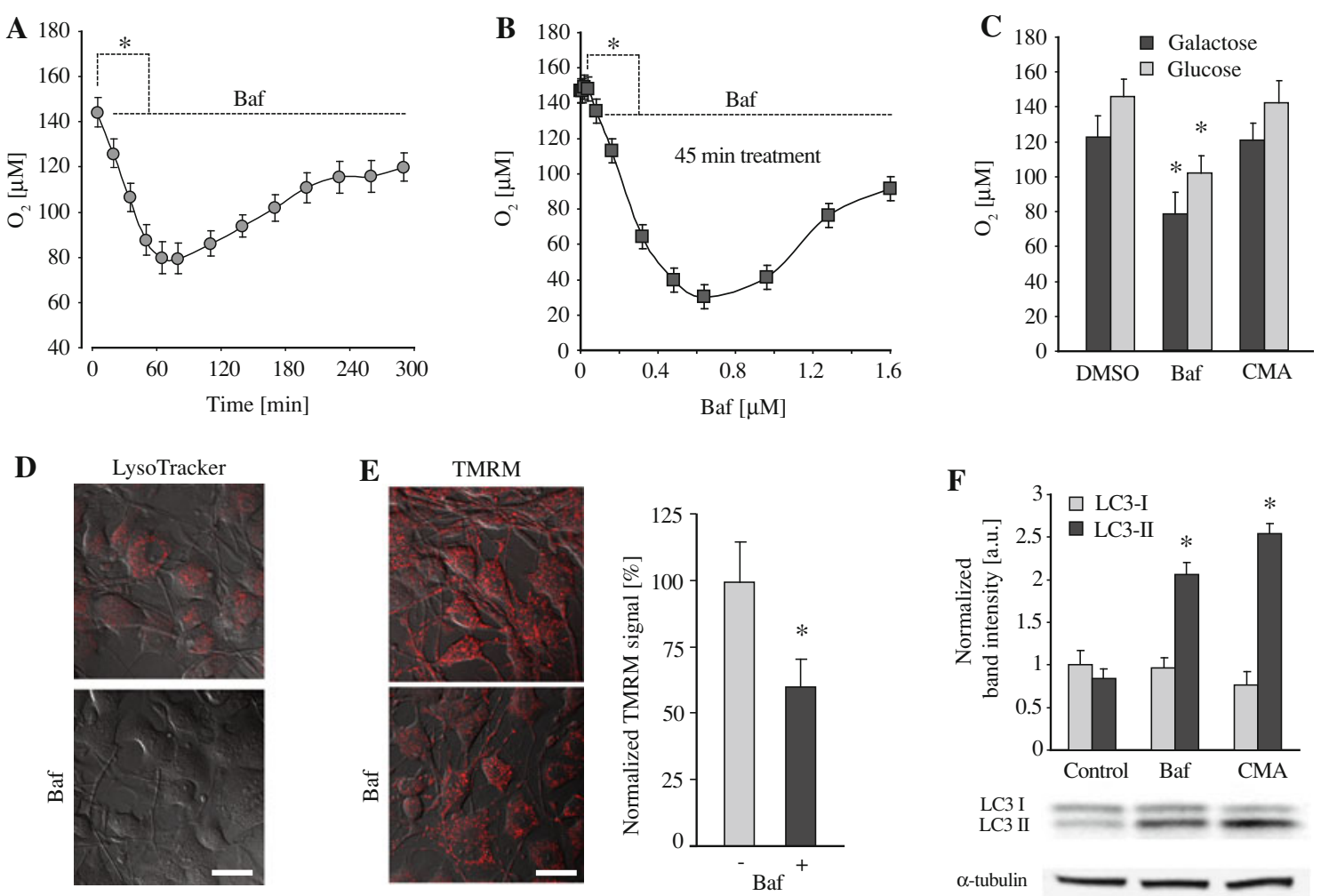

Fig. 1 The effect of Baf on the respiration of ${ }_{d} \mathrm{PC} 12$ cells is attributed to mitochondrial uncoupling. a As a result of sustained activation of respiration by Baf $(0.25 \mu \mathrm{M})$, cellular $\mathrm{O}_{2}$ levels steadily decrease for 60-80 min and then remain elevated for hours. b Dose-dependent decrease in cellular $\mathrm{O}_{2}$ measured $45 \mathrm{~min}$ after Baf application reveals that the respiratory response reaches a maximum at $0.5-0.8 \mu \mathrm{M}$ Baf. c Cell deoxygenation induced by Baf increases when glucose in the medium is replaced with galactose. In contrast, $0.25 \mu \mathrm{M}$ CMA has no effect. d Complete dissipation of the acidic compartments after

(not shown). If Baf was subsequently removed from the medium, respiration returned to the basal level.

When the cells were treated with $0.25 \mu \mathrm{M}$ CMA (another V-ATPase inhibitor, which does not uncouple the mitochondria), no changes in cell oxygenation and respiration were seen (Fig. 1c), while the dissipation of acidic lysosomal compartments was similar to that seen with Baf (Fig. 1d, shown for Baf). This indicates that the respiratory response to Baf is not a consequence of V-ATPase inhibition. To confirm this, we inhibited V-ATPase via the dissociation of V0 and V1 domains prior to Baf treatment by replacing glucose in the medium with galactose [44]. Galactose also dramatically reduces the glycolytic ATP production and increases OxPhos [20], thus causing a significant decrease in cellular $\mathrm{O}_{2}$. We found that in the cells preconditioned for 3-4 h on galactose, Baf induced even higher deoxygenation (Fig. 1c) signifying that the activation of $\mathrm{O}_{2}$ consumption is not related to V-ATPase integrity and activity.

Uncoupling by the classical uncoupler FCCP or the $\mathrm{K}^{+}$ionophore valinomycin is normally associated with
30 min treatment with $0.25 \mu \mathrm{M}$ Baf is confirmed by LysoTracker Red staining. e The intensity of the $\Delta \Psi \mathrm{m}$-sensitive probe TMRM decreases by $30-50 \%$ when the cells are incubated with $0.25 \mu \mathrm{M}$ Baf for $30 \mathrm{~min}$. f In the cells treated with Baf or CMA for $4 \mathrm{~h}$ under starving conditions the level of LC3 II degradation decreases due to inhibition of autophagy. DMSO was used as a negative control. In d and e representative live cell confocal images are shown. Bar $20 \mu \mathrm{m}$; asterisks significant differences

complete dissipation of the mitochondrial membrane potential $(\Delta \Psi \mathrm{m})$. However, treatment of ${ }_{\mathrm{d}} \mathrm{PC} 12$ cells with $0.25 \mu \mathrm{M}$ Baf for 30-60 min decreased the TMRM signal only by $40 \pm 10 \%$ (Fig. 1e). Under these conditions a large proportion of the mitochondria underwent substantial transformation from an elongated $(5 \pm 3$ to $0.2 \pm 0.1 \mu \mathrm{m})$ to a more round $(3 \pm 2$ to $0.4 \pm 0.2 \mu \mathrm{m})$ shape. The decrease in TMRM signal reflected only changes in $\Delta \Psi \mathrm{m}$ polarization, since plasma membrane potential $(\Delta \Psi \mathrm{p})$ assessed using the $\operatorname{DiSBAC}_{2}(3)$ probe remained unaffected (not shown). A substantial drop in JC-1 probe fluorescence confirmed significant depolarization of $\Delta \Psi \mathrm{m}$ (Supplementary Fig. S1).

Dissipation of lysosomes by Baf and CMA was coupled with significant inhibition of autophagic flux (seen as an increase in cellular LC3A/B II levels, Fig. 1f), and an increase in ROS production (Fig. 2a, b; Supplementary Fig. S2). Both inhibition of autophagy and elevation of ROS are known to activate apoptosis. We found that caspase-3 activity (marker of apoptosis) was increased by 150-200\% and about $100 \%$ after $4 \mathrm{~h}$ of treatment with Baf 


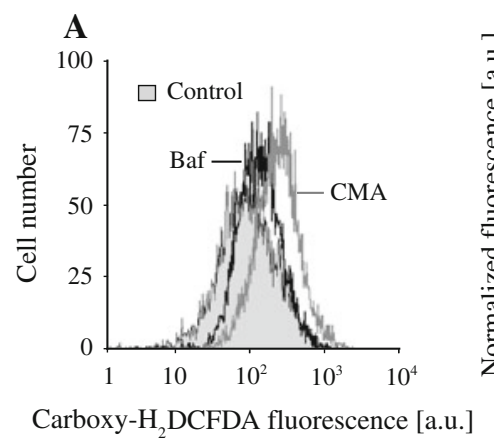

Fig. 2 The effect of Baf on generation of ROS and apoptosis of ${ }_{\mathrm{d}} \mathrm{PC} 12$ cells. a FACS analysis of ROS-sensitive carboxy- $\mathrm{H}_{2}$ DCFDA probe fluorescence reveal an increase in ROS levels in the cells treated with Baf and CMA (both $0.25 \mu \mathrm{M}$ ) for $2 \mathrm{~h}$. b Quantitative analysis of data presented in a as compared to the effect of classical
ROS inducer tert-butyl hydroperoxide (TBHP, $250 \mu \mathrm{M}$ ). c Caspase-3 activity was increased in the cells treated with both V-ATPase inhibitors for $4 \mathrm{~h}$; however, the effect of Baf was significantly stronger. Asterisks significant differences

contrast, CMA did not influence ATP levels even in the absence of glycolytic ATP supply (not shown). A similar decrease in ATP upon Baf treatment in galactose $(+)$ medium was seen in ${ }_{d} \mathrm{SH}-\mathrm{S}$ Y5Y cells (Supplementary Fig. S5). Interestingly, an additional decrease in ATP of about $20 \%$ was observed in $\mathrm{Baf}(+){ }_{\mathrm{d}} \mathrm{PC} 12$ cells upon inhibition of F0F1 ATP synthase (mitochondrial complex V) with $10 \mu \mathrm{M}$ oligomycin (Fig. 3d). This suggests that although Baf uncoupled $\mathrm{O}_{2}$ consumption from ATP production, the cells were still able to produce ATP through OxPhos, at least at $<0.25 \mu \mathrm{M}$ Baf.

To confirm this, we analysed the changes in respiration, $\Delta \mathrm{pHm}$ and $\Delta \Psi \mathrm{m}$, induced in $\mathrm{Baf}(+){ }_{\mathrm{d}} \mathrm{PC} 12$ cells by oligomycin. Normally, inhibition of ATP synthase (the main consumer of the $\mathrm{H}^{+}$gradient across the mitochondrial membrane) reduces $\mathrm{O}_{2}$ consumption and leads to a rapid and sustained increase in $\Delta \mathrm{pHm}$ [45]. We observed a 10-20\% decrease in the respiratory response to Baf in the cells pretreated with oligomycin (Fig. 4a). Using the mitochondrial $\mathrm{pH}$ probe mtAlpHi [33], we found that oligomycin transiently elevated mitochondrial $\mathrm{pH}$ in $\mathrm{Baf}(+)$ cells (Fig. 4b). Being significantly smaller than in the control, this increase suggests that complexes I-IV of the electron transport chain (ETC) generate notable $\mathrm{H}^{+}$gradients it the mitochondria uncoupled by Baf. This result also shows that in the presence of Baf, ATP synthase still works in direct mode utilising $\mathrm{H}^{+}$gradients for ATP production. On the other hand, after oligomycin addition, the intensity of TMRM in $\mathrm{Baf}(+)$ cells gradually decreased (Fig. 4c), indicating that the complex $\mathrm{V}$ also participates in the maintenance of $\Delta \Psi \mathrm{m}$ acting as an ATPase.

Finally, we found that upon addition of FCCP to Baf $(+)$ cells, the relative drop in mtAlpHi fluorescence was similar to that of the control (Fig. 4d), thus confirming that a large proportion of the $\Delta \mathrm{pH}$ is retained by the mitochondria. The relative decrease in TMRM signal induced by FCCP in

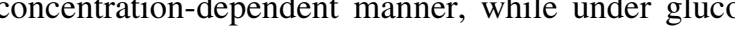
conditions they remained unchanged (Fig. 3c, d). In 
Fig. 3 Baf activates glycolysis and reduces ATP production by OxPhos in ${ }_{\mathrm{d}} \mathrm{PC} 12$ cells. a In the cells treated with $0.25 \mu \mathrm{M}$ Baf and CMA for $30 \mathrm{~min}$, cytosolic $\mathrm{pH}$ decreases. Live-cell imaging of the BCECF distribution within the cells reveals focal condensation of the probe. b Extracellular acidification rate $(E C A)$, which is linked to the rate of glycolysis, increases in the cells treated with $0.25 \mu \mathrm{M}$ Baf to the levels characteristic of valinomycin $(\mathrm{Val}, 0.25 \mu \mathrm{M})$ or FCCP $(F C C P, 0.5 \mu \mathrm{M})$ uncoupling. CMA $(0.25 \mu \mathrm{M})$ does not change the extracellular acidification. c, $\mathbf{d}_{\mathrm{d}} \mathrm{PC} 12$ cells grown in galactose $(+)$ conditions show a decrease in their ATP levels in a Baf concentration-dependent manner (c) and a timedependent manner (d). In glucose $(+)$ medium Baf does not affect cellular ATP levels. Inhibition of the F0F1 ATPase by oligomycin $(10 \mu \mathrm{M})$ further reduces the ATP levels. DMSO was used as a negative control. Asterisks significant differences
A
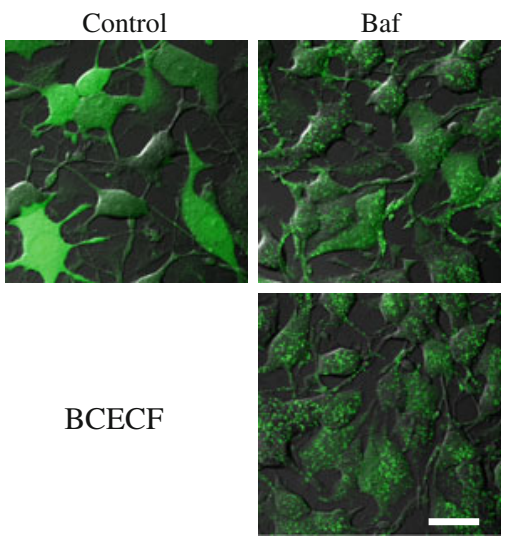

CMA

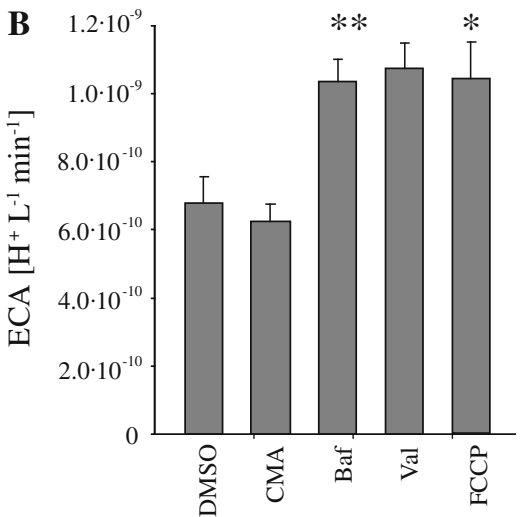

C

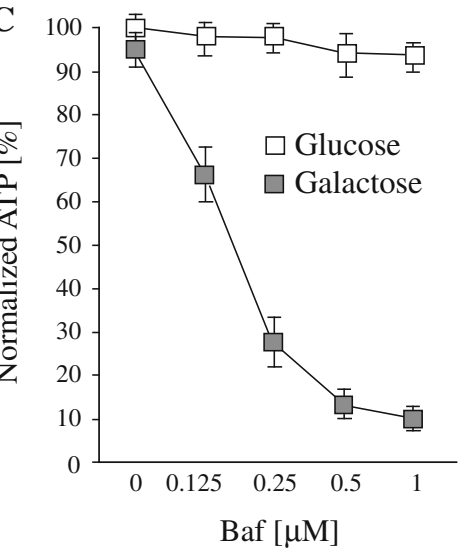

D

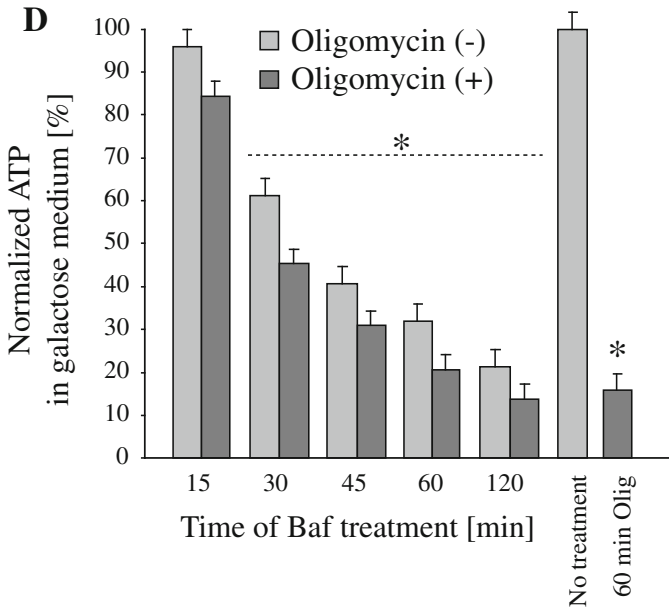

Baf $(+)$ cells was significantly smaller than in the control, confirming partial depolarization of $\Delta \Psi \mathrm{m}$ in $\mathrm{Baf}(+)$ cells (see Fig. 1e).

Taken together, these data indicate that mitochondrial uncoupling induced by Baf is associated with large perturbations in cellular metabolism and energy balance.

\section{Bafilomycin A1 induces flickering depolarization} of the mitochondria in ${ }_{\mathrm{d}} \mathrm{PC} 12$ cells

The marked decrease in cellular TMRM signal upon Baf treatment (Fig. 1e) can be interpreted as partial depolarization of the whole mitochondrial pool of the cell. However, when analysing confocal images for spatial distribution of TMRM $(\Delta \Psi \mathrm{m})$ and ${ }_{\text {mito }}$ Case12 (mitochondrial $\mathrm{Ca}^{2+}$ ) within individual cells, we found a significant $(25 \pm 10 \%)$ decrease in their colocalization $45 \mathrm{~min}$ after Baf addition (Fig. 5a). Since the mito Case 12 probe has no tendency to leak (being a mitochondria-targeted protein), this result pointed to a decrease in the proportion of polarized mitochondria, rather than a more general partial depolarization. Indeed, further analysis of the TMRM signal in individual mitochondria in ${ }_{\mathrm{d}} \mathrm{PC} 12$ cell neurites visualized by mito Case12, revealed random, flickering depolarization, which can be seen $10 \mathrm{~min}$ after Baf application and lasts for several hours (Fig. 5b, c; Supplementary movie). In galactose $(+)$ medium the flickering developed even more rapidly (within $5 \mathrm{~min}$ in individual cells). Although such flickering had rather high interexperiment variability complicating its detailed statistical analysis, it was clearly visible after 45-min incubation with Baf in about 15-55\% of cells, and progressed to about $100 \%$ of the cell population in 1-3 h. Detailed time-lapse image analysis of cells after $1 \mathrm{~h}$ of Baf treatment (images taken every $0.5 \mathrm{~s}$ ) revealed that $\Delta \Psi \mathrm{m}$ flickering between the polarized and depolarized states occurred with an average period of $20 \pm 10 \mathrm{~s}$ (Supplementary Fig. S6). Marked fluctuations in TMRM fluorescence $(90 \pm 5 \%)$ showed that most individual mitochondria underwent full depolarization and restoration of the $\Delta \Psi \mathrm{m}$. In control cells, transient fluctuations in TMRM signal without prominent flickering were observed in $<3 \%$ of cells. Confocal images recorded at different sampling frequencies (every 5-20 s) showed that $\Delta \Psi \mathrm{m}$ fluctuations were independent of illumination of the 

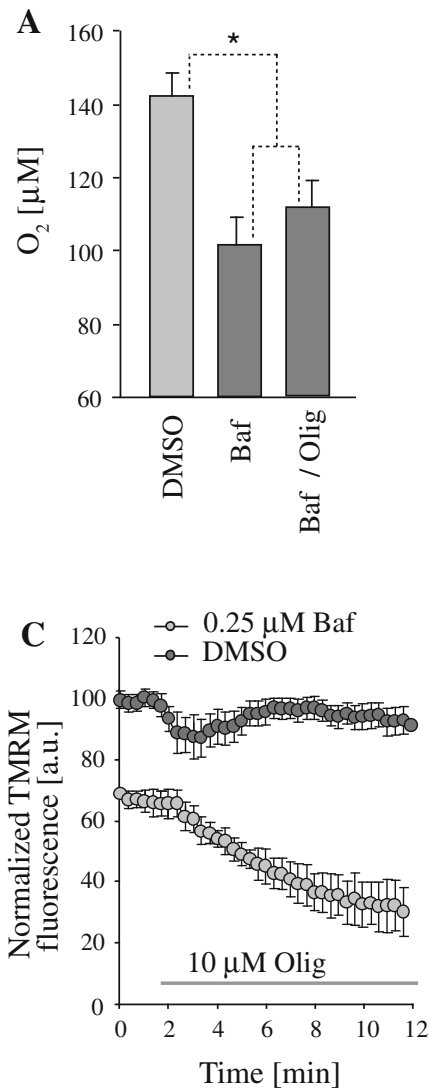
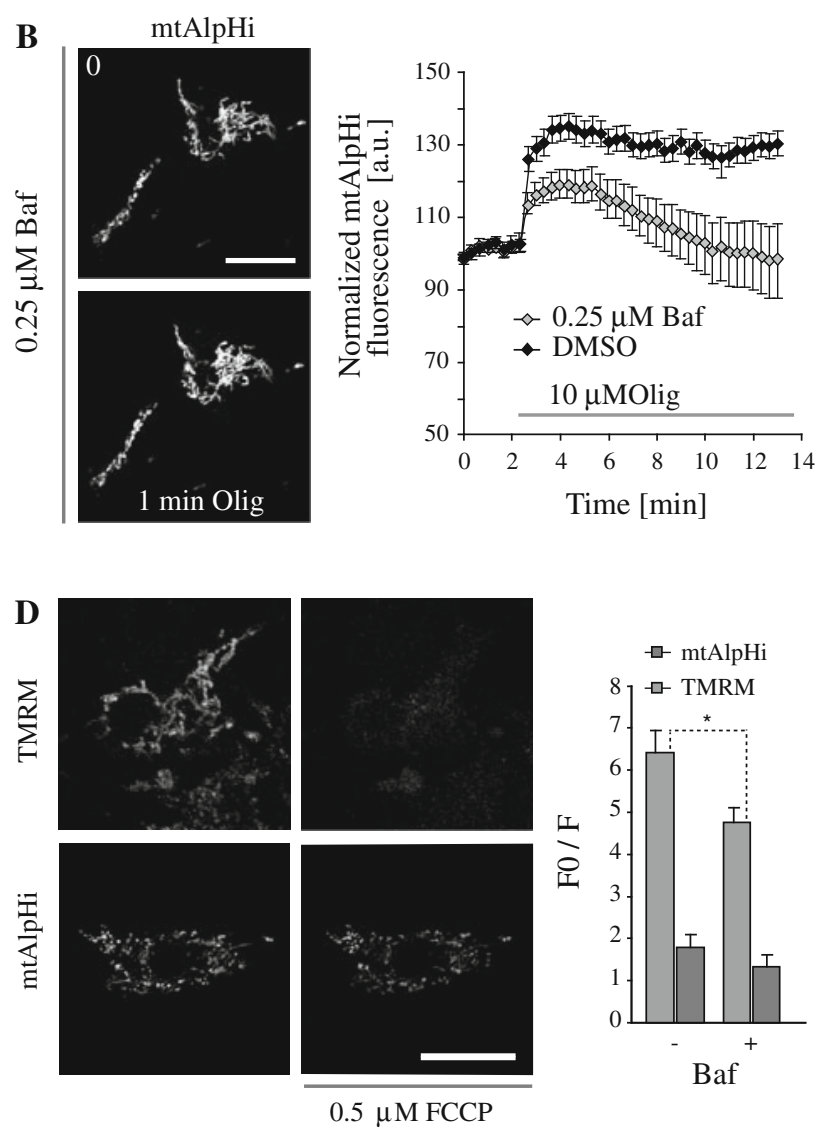

Fig. 4 Baf reduces $\Delta \mathrm{pHm}$ and $\Delta \Psi \mathrm{m}$ in ${ }_{\mathrm{d}} \mathrm{PC} 12$ cells. a Inhibition of the F0F1 ATPase with oligomycin $(10 \mu \mathrm{M})$ decreases Baf-specific cell deoxygenation by 10-20\%. b Oligomycin treatment significantly elevates the fluorescence of the mtAlpHi probe in control cells, indicating a sustained matrix alkalinization. In $\mathrm{Baf}(+)$ cells the increase in $\Delta \mathrm{pH}$ is lower and not sustainable. $\mathbf{c}$ TMRM profiles show a gradual decrease in probe fluorescence in $\mathrm{Baf}(+)$ cells upon addition of oligomycin. d Uncoupling with $0.5 \mu \mathrm{M}$ FCCP causes a drop in TMRM and mtAlpHi fluorescence in $\mathrm{Baf}(+)$ cells,

TMRM probe (which can also depolarize mitochondria upon photoactivation [46]).

We also observed fluctuations in mito Case12 fluorescence of around 10-25\% (Fig. 5d, e), mostly in-phase with the changes in $\Delta \Psi \mathrm{m}$. This synchronism was to be expected, since mitochondrial $\mathrm{Ca}^{2+}$ uptake can depolarize $\Delta \Psi \mathrm{m}$ $[47,48]$. In turn, $\Delta \Psi \mathrm{m}$ depolarization inhibits $\mathrm{Ca}^{2+}$ influx through the electrogenic mitochondrial $\mathrm{Ca}^{2+}$ uniporter [49] and shifts the balance of the mitochondrial $\mathrm{Ca}^{2+}$ fluxes towards $\mathrm{Ca}^{2+}$ extrusion. Since the endoplasmic reticulum (ER) is considered to be the main contributor to mitochondrial $\mathrm{Ca}^{2+}$ fluxes [50,51], we studied the role of this compartment in the Baf-specific flickering. Figure $5 \mathrm{f}$ shows that inhibition of sarco/endoplasmic reticulum $\mathrm{Ca}^{2+}$ ATPase (SERCA) with thapsigargin noticeably changed the morphology of mitochondria in ${ }_{\mathrm{d}} \mathrm{PC} 12$ cells treated with Baf. After $1 \mathrm{~h}$ of thapsigargin/30 min of Baf demonstrating a decrease in the $\Delta \Psi \mathrm{m}$ and $\Delta \mathrm{pH}$, respectively $(F 0 / F$ represents the ratio of fluorescence before and 3 min after FCCP addition). The decrease in mtAlpHi signal does not depend on Baf treatment; in contrast, the relative drop in TMRM signal in $\mathrm{Baf}(+)$ cells is significantly smaller than in the control. In all experiments except that shown in a, cells were preincubated with $0.25 \mu \mathrm{M}$ Baf for 45 min prior to the addition of oligomycin or FCCP. DMSO was used as a negative control. Bars $20 \mu \mathrm{m}$; asterisks significant differences

treatment, the mitochondria were transformed into large round structures (1.5-3.5 $\mu \mathrm{m}$ in diameter), which could be seen on the DIC images. TMRM staining remained intense (Fig. 5f, g) and became more diffuse, whereas the amplitude and frequency of flickering decreased. When Baf was applied to cells pretreated with thapsigargin for $30 \mathrm{~min}$, this effect started to develop within 7-10 min (Supplementary Fig. S7). Thapsigargin alone did not affect the morphology and polarization of the mitochondria. These results demonstrate the importance of the ER in the development of stochastic $\Delta \Psi \mathrm{m}$ fluctuations and in the maintenance of mitochondrial function.

One of the mechanisms proposed for $\mathrm{Ca}^{2+}$-mediated fluctuations in $\Delta \Psi \mathrm{m}$ is transient opening of the PTP [52]. Similarly, PTP opening followed by $\Delta \Psi \mathrm{m}$ depolarization has been described for mitochondria overloaded with $\mathrm{K}^{+}$ [53]. To investigate the contribution of PTP to the $\Delta \Psi \mathrm{m}$ 


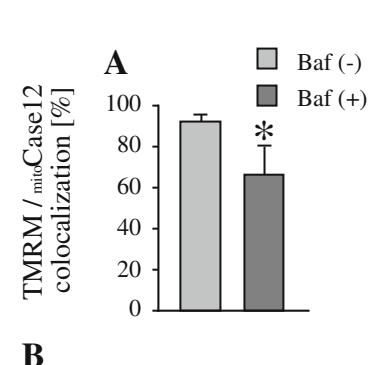

C
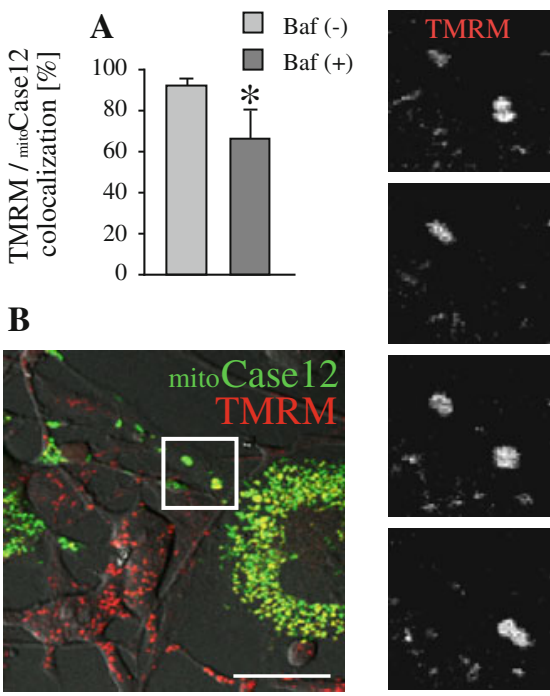

F DMSO

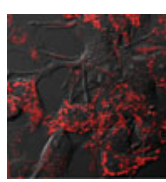

$\mathrm{Baf} / \mathrm{CsA}$
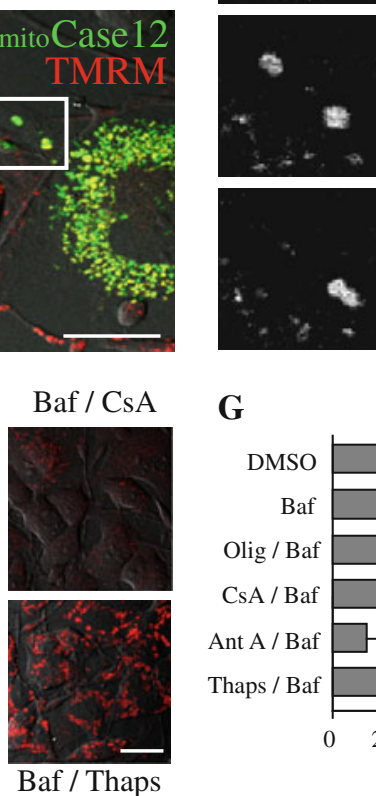

G
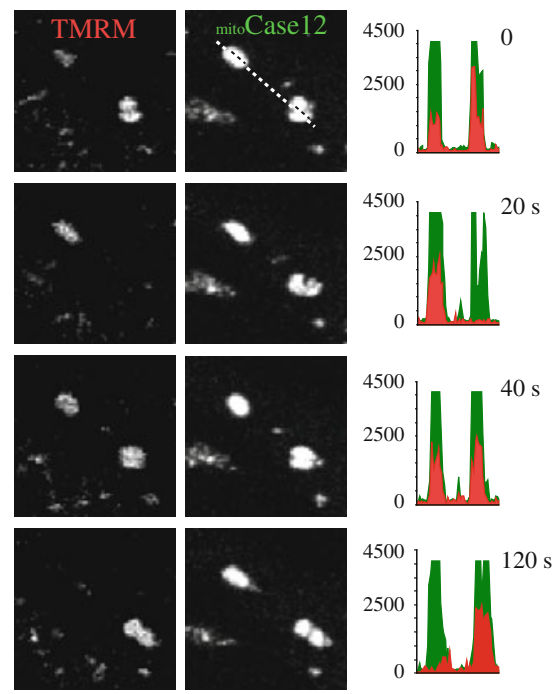

D

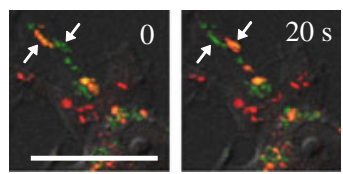

$\mathrm{TMRM} / \mathrm{mito}$ Case 12
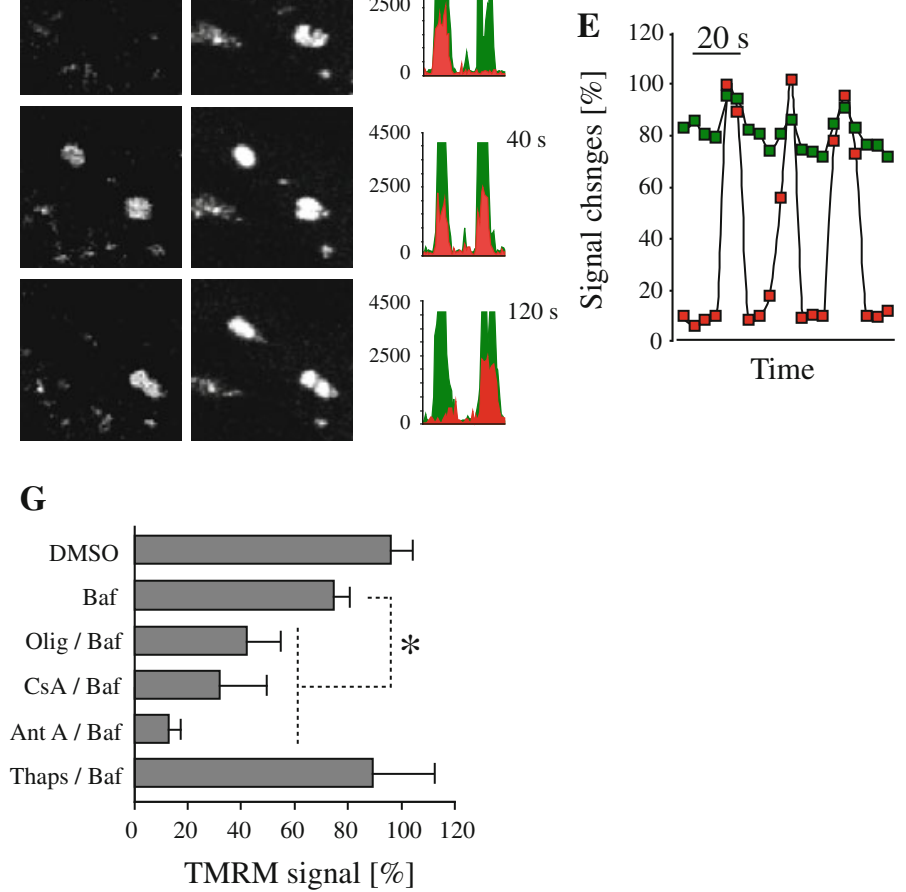

Fig. 5 Baf induces flickering depolarization of the $\Delta \Psi \mathrm{m}$ in ${ }_{\mathrm{d}} \mathrm{PC} 12$ cells. a Colocalization of the TMRM and ${ }_{\text {mito }}$ Case 12 probes in cells treated with Baf for 45 min decreases from $90-95 \%$ to $50-80 \%$. b, c Large fluctuations of TMRM signals in individual mitochondria located in cell neurites and costained with mito Case12 probe (b inset) reveal a flickering pattern of $\Delta \Psi \mathrm{m}$ depolarization. The dashed line (c) shows a cross-section of representative mitochondria selected for analysis. d, e In individual mitochondria localized in neurites (d arrows), TMRM intensity periodically drops by $90 \pm 5 \%$ and then returns to the basal level, while the mito Case12 fluorescence shows $15-25 \%$ fluctuations. f Inhibition of PTP opening by CsA $(2 \mu \mathrm{M})$ strongly increases the effect of Baf on $\Delta \Psi \mathrm{m}$ depolarization.

flickering, we applied Baf to ${ }_{\mathrm{d}} \mathrm{PC} 12$ cells pretreated with cyclosporine A (CsA, $2 \mu \mathrm{M})$, which binds cyclophilin D and prevents the formation of PTP. CsA itself did not affect the polarization of mitochondria, but dramatically increased the effect of $\mathrm{Baf}$ on the $\Delta \Psi \mathrm{m}$ (Fig. 5f, g). Monitored after $1 \mathrm{~h}$ of the double treatment, the majority of cells lost TMRM staining, and only a minor population of the mitochondria revealed the characteristic flickering of $\Delta \Psi$ m with low TMRM intensity. When Baf was applied to cells pretreated with CsA for $30 \mathrm{~min}$, it triggered depolarization and flickering of the $\Delta \Psi \mathrm{m}$ within minutes, whereas after $15 \mathrm{~min}$ TMRM staining decreased by $70 \pm 20 \%$ (Fig. $5 \mathrm{~g}$ ). The effect of CsA on $\Delta \Psi \mathrm{m}$ depolarization by Baf was dose-dependent and barely visible at
In contrast, thapsigargin $(10 \mu \mathrm{M}$, Thaps $)$ does not change the effect of Baf on the TMRM signal. However, the morphology of the mitochondria changes dramatically: they become large round compartments with an average diameter of $1-2 \mu \mathrm{m}$. g 15 min after the addition of Baf to the cells preincubated with CsA, TMRM intensity decreases to $15-50 \%$, which is significantly different to the cells treated with Baf alone. Inhibition of F0F1 ATPase with oligomycin $(10 \mu \mathrm{M}$, Olig $)$ has a similar effect. Antimycin A completely depolarizes the mitochondria. Thapsigargin strongly increases variability of the response to Baf. All preincubations were done for $30 \mathrm{~min}$. DMSO was used as a negative control. Bar $20 \mu \mathrm{m}$; asterisks significant differences

CsA concentrations $<0.75 \mu \mathrm{M}$. Finally, CsA did not inhibit activation of caspase- 3 by Baf (data not shown).

Since $\Delta \Psi \mathrm{m}$ and F0F1 ATP synthase activity are reciprocally regulated, the latter can modulate $\Delta \Psi \mathrm{m}$ flickering. We inhibited ATP synthase with oligomycin and observed a fast progressive decrease in TMRM fluorescence after Baf addition, with only minor reductions in flickering. When the mitochondrial complex III was inhibited by antimycin $\mathrm{A}$, mitochondria lost $\Delta \Psi \mathrm{m}$ within 5-7 min after Baf addition without any flickering (not shown).

Overall, we concluded that the characteristic random $\Delta \Psi \mathrm{m}$ flickering of individual mitochondria in PC12 cells is associated with Baf uncoupling. 
The interplay between bafilomycin $\mathrm{A} 1$ and $\mathrm{Ca}^{2+}$ in the regulation of respiration

In ${ }_{\mathrm{d}} \mathrm{PC} 12$ cells treated with $0.25 \mu \mathrm{M}$ Baf for $30 \mathrm{~min}$ or longer, we observed a dramatic elevation of cytosolic $\mathrm{Ca}^{2+}$, seen as an increase of $140 \pm 40 \%$ in Fluo- 4 fluorescence (Fig. 6a). In approximately $30 \%$ of the cells, Fluo-4 fluorescence was distributed diffusely throughout the cytoplasm, including neurites. More than $50 \%$ of the cells had bright punctate Fluo-4 staining with poorly identifiable localization. Over time, the distribution of cytosolic $\mathrm{Ca}^{2+}$ became more uneven and punctate. A similar effect was observed in ${ }_{\mathrm{d}} \mathrm{SH}-\mathrm{SY} 5 \mathrm{Y}$ and CGN cells (not shown).

Since the $\Delta \Psi \mathrm{p}$ remained relatively unchanged upon Baf treatment, $\mathrm{Ca}^{2+}$ influx through voltage-gated calcium channels was ruled out. Therefore, the increase in cytosolic $\mathrm{Ca}^{2+}$ was provided by intracellular stores. The two candidate organelles affected by Baf directly are the acidic compartments and the mitochondria. Indeed, the impairment of V-ATPase activity dissipates the $\mathrm{H}^{+}$gradients across the membrane and abolishes the deposition of $\mathrm{Ca}^{2+}$ into acidic stores. On the other hand, it is known that partial depolarization of $\Delta \Psi \mathrm{m}$ and decrease in matrix $\mathrm{pH}$ can inhibit $\mathrm{Ca}^{2+}$ influx into the mitochondria and activate $\mathrm{Ca}^{2+}$ release through the mitochondrial $\mathrm{Na}^{+} / \mathrm{Ca}^{2+}$ exchanger $\left({ }_{\mathrm{m}} \mathrm{NCX}\right)$ $[49,54]$. In assessing this, we found that the pool of acidic compartments is the main contributor to the elevation of cytosolic $\mathrm{Ca}^{2+}$, because the inhibition of V-ATPase with CMA caused a similar increase in Fluo-4 fluorescence (not shown). To estimate the contribution of mitochondria to sustained elevation of cytosolic $\mathrm{Ca}^{2+}$ and the long-term effect on mitochondrial $\mathrm{Ca}^{2+}$ levels, we preincubated ${ }_{\mathrm{d}} \mathrm{PC} 12$ cells with Baf for $1-2 \mathrm{~h}$ and then treated with FCCP $(0.5 \mu \mathrm{M})$, which is known to induce a drop in the mitochondrial $\mathrm{Ca}^{2+}$ [55]. A large and rapid decrease in mito Case12 fluorescence was observed irrespective of Baf pretreatment (Fig. 6b), suggesting that mitochondria retained a large proportion of $\mathrm{Ca}^{2+}$ after the prolonged exposure of cells to Baf.

High cytosolic $\mathrm{Ca}^{2+}$ increases $\mathrm{Ca}^{2+}$ fluxes and intercompartmental $\mathrm{Ca}^{2+}$ exchange, thus regulating cell metabolism and particularly OxPhos [56]. Considering the persistent fluctuations in mitochondrial $\mathrm{Ca}^{2+}$ (Fig. 5d, e), we examined the role of $\mathrm{Ca}^{2+}$ fluxes in the respiratory response to Baf. The increase in respiration was completely abolished by blocking cytosolic $\mathrm{Ca}^{2+}$ fluctuations with the intracellular chelator BAPTA (Fig. 6c) or by inhibiting the SERCA with thapsigargin $(10-15 \mu \mathrm{M})$. A similar effect was observed when the SERCA was inhibited by BHQ $(50 \mu \mathrm{M})$. The effect of Baf was partially decreased by CGP37157 (inhibitor of the $\left.{ }_{\mathrm{m}} \mathrm{NCX}, 10-15 \mu \mathrm{M}\right)$. In contrast, neither the removal of extracellular $\mathrm{Ca}^{2+}$ with EGTA nor the inhibition of plasma membrane $\mathrm{Ca}^{2+}$-ATPase with $100 \mu \mathrm{M}$ caloxin $1 \mathrm{C} 2$ [57] affected the respiratory response to Baf. This reveals that respiration is increased by a mechanism independent of $\mathrm{Ca}^{2+}$ fluxes across the plasma membrane.

Taken together, the respiratory response to Baf, although attributed to mitochondrial uncoupling, is strongly regulated by the cytosolic $\mathrm{Ca}^{2+}$ fluxes and the $\mathrm{Ca}^{2+}$ buffering capacity of cellular compartments, particularly the ER which is the main partner for $\mathrm{Ca}^{2+}$ exchange with mitochondria.

\section{Bafilomycin A1 increases cell susceptibility} to excitatory stimulation

Mitochondrial uncoupling increases the risk of energy crisis upon cell excitation, while for the cells lacking acidic
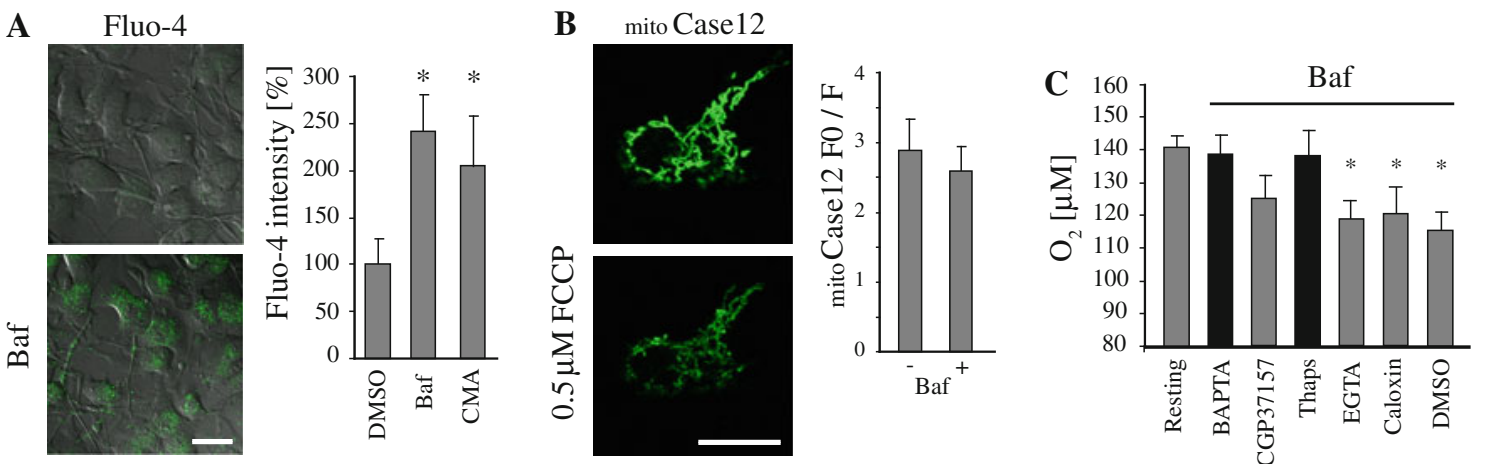

Fig. 6 The interplay between $\mathrm{Baf}$ and $\mathrm{Ca}^{2+}$ in ${ }_{\mathrm{d}} \mathrm{PC} 12$ cell. a Cytosolic $\mathrm{Ca}^{2+}$ levels increase dramatically after 45-60 min of treatment with $0.25 \mu \mathrm{M}$ Baf, as detected with the Fluo-4 probe. b Uncoupling with $0.5 \mu \mathrm{M}$ FCCP causes a dramatic drop in mito Case 12 fluorescence in $\mathrm{Baf}(+)$ cells, indicating a deep decrease in mitochondrial $\mathrm{Ca}^{2+}$, similar to that seen in the control. c The effect of Baf on cell respiration is abolished by increasing the $\mathrm{Ca}^{2+}$ buffering capacity of the cytosol with $25 \mu \mathrm{M}$ BAPTA-AM or by inhibiting the SERCA with $10 \mu \mathrm{M}$ thapsigargin. The respiratory response is not changed under extracellular $\mathrm{Ca}^{2+}$-free conditions, or upon inhibition of plasma membrane $\mathrm{Ca}^{2+}$-ATPase with caloxin $1 \mathrm{C} 2(100 \mu \mathrm{M})$. It is not significantly downregulated by the inhibition of mitochondrial $\mathrm{Na}^{+}$/ $\mathrm{Ca}^{2+}$ exchanger with CGP37157 $(10 \mu \mathrm{M})$. DMSO was used as a negative control. Bars $20 \mu \mathrm{m}$; asterisks significant differences 
compartments and overloaded with $\mathrm{Ca}^{2+}$ the risk increases further. We investigated how Baf affects respiratory responses to excitatory stimuli.

Depolarization of the $\Delta \Psi \mathrm{p}$ by high $\mathrm{K}^{+}$triggers a rapid transient decrease in the $\mathrm{O}_{2}$ level and substantial elevation of ATP level in ${ }_{\mathrm{d}} \mathrm{PC} 12$ cells, which reaches a maximum in 2-5 min after $\mathrm{K}^{+}$addition [28]. Preincubation with Baf significantly increased the respiratory response to $\mathrm{K}^{+}$ (Fig. 7a, b). This increase was further augmented by thapsigargin. Under extracellular $\mathrm{Ca}^{2+}$-free conditions the response of Baf-treated cells to $\mathrm{K}^{+}$was abolished (Fig. 7b). While measuring the changes in ATP levels induced by high $\mathrm{K}^{+}$, we found that in Baf-treated cells grown on glucose the characteristic increase in ATP was partially inhibited (Fig. 7c), whereas under galactose $(+)$ conditions the addition of $\mathrm{K}^{+}$caused a significant drop in cellular ATP. Pretreatment with CMA did not change the respiratory response and slightly reduced the ATP response to $\mathrm{K}^{+}$. For comparison, valinomycin $(0.25 \mu \mathrm{M})$ did not affect the ATP response to $\mathrm{K}^{+}$in glucose $(+)$medium, while under galactose $(+)$ conditions it dramatically reduced ATP irrespective of $\mathrm{K}^{+}$addition.

Glutamate was shown to induce cytotoxicity in PC12 cells [58]. We applied 5, 10 and $20 \mathrm{mM}$ glutamate to $\mathrm{Baf}(+)$ and $\mathrm{Baf}(-){ }_{\mathrm{d}} \mathrm{PC} 12$ cells and found that Baf significantly increased the respiratory response to glutamate (Fig. 7d). Moreover, Baf markedly reduced the viability of the cells, treated with glutamate (Fig. 7e); determined by measuring total cellular ATP levels $20 \mathrm{~h}$ after glutamate application, cell viability decreased with the elevation of glutamate. These effects were not observed in the cells treated with CMA.

These results demonstrate that susceptibility of $\operatorname{Baf}(+)$ ${ }_{\mathrm{d}} \mathrm{PC} 12$ cells to excitatory stimulation increases significantly, while their energy demand upon excitation is not met by the ATP production.
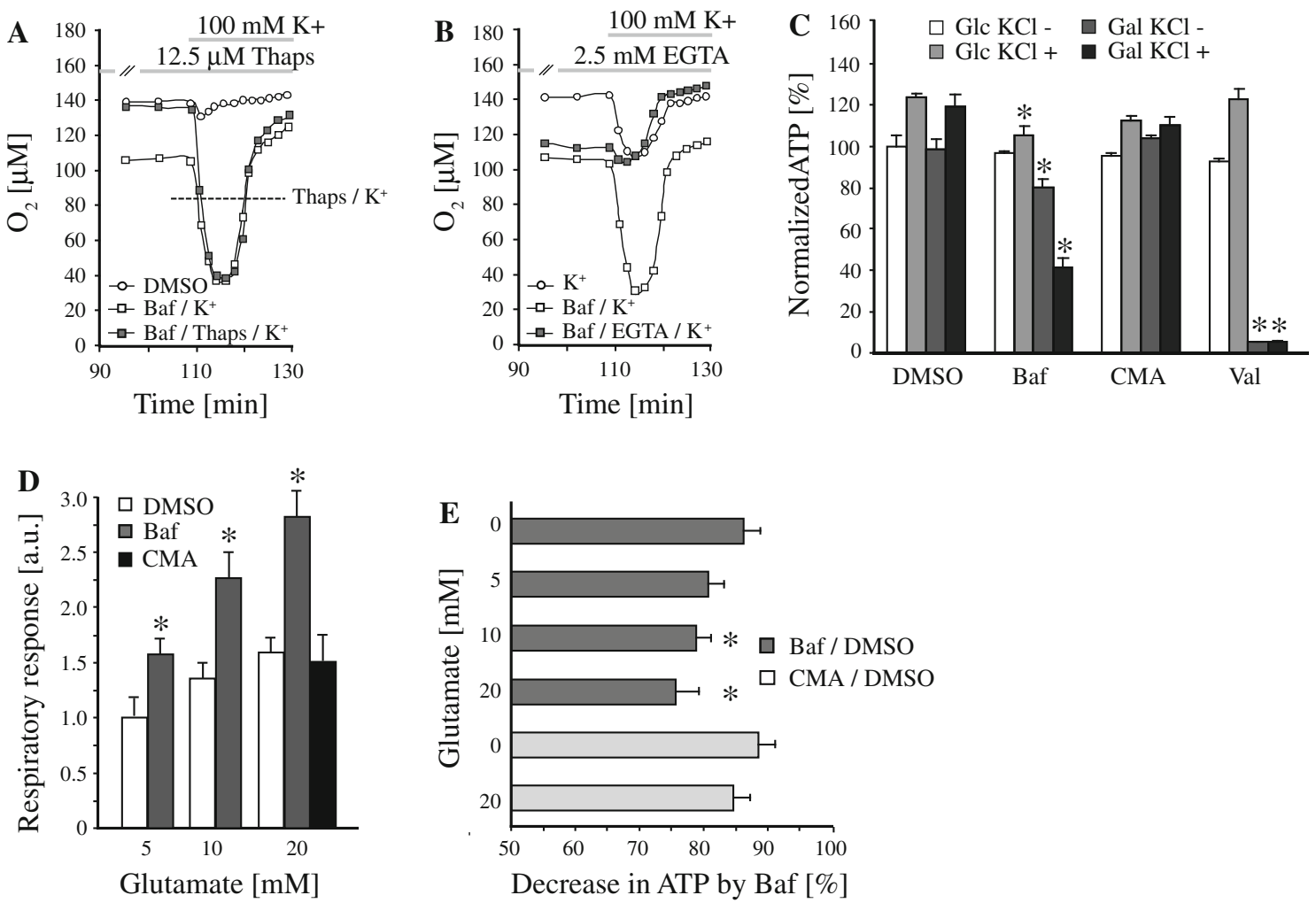

Fig. 7 Baf increases susceptibility of ${ }_{\mathrm{d}} \mathrm{PC} 12$ to excitatory stimulation. a Pretreatment with $0.25 \mu \mathrm{M}$ Baf dramatically increases the respiratory response to $\Delta \Psi \mathrm{p}$ depolarization by high $\mathrm{K}^{+}$. The response is not reduced by the SERCA inhibitor thapsigargin. The dashed line shows the level of deoxygenation induced by $\mathrm{K}^{+}$in the $\mathrm{Baf}(-)$ cells treated with thapsigargin. $\mathbf{b}$ In $\mathrm{Ca}^{2+}$-free medium $\mathrm{Baf}(+)$ cells do not respond to high $\mathrm{K}^{+}$and rapidly loose their respiratory activity. c Pretreatment with Baf $(25 \mu \mathrm{M}, 30 \mathrm{~min})$ in glucose $(+)$ medium reduces elevation of ATP in response to $\Delta \Psi$ p depolarization by high $\mathrm{K}^{+}$, whereas in galactose $(+)$medium $\mathrm{K}^{+}$stimulation strongly decreases cellular ATP. The effect of CMA $(0.25 \mu \mathrm{M})$ on the ATP response to $\mathrm{K}^{+}$is less pronounced. Valinomycin $(\mathrm{Val}, 0.25 \mu \mathrm{M})$ in galactose $(+)$ conditions reduces the ATP by $>90 \%$, irrespective of $\mathrm{K}^{+}$treatment. d Pretreatment of the cells with $25 \mu \mathrm{M}$ Baf for $30 \mathrm{~min}$ amplifies the dose-dependent response to glutamate $(5-20 \mathrm{mM})$, while CMA does not affect the response to glutamate. e Relative decrease in cellular ATP (measured $20 \mathrm{~h}$ after glutamate treatment) reveals a negative effect of Baf on the viability of ${ }_{\mathrm{d}} \mathrm{PC} 12$ cells, exposed to glutamate. DMSO was used as a negative control. Asterisks significant differences 


\section{Discussion}

Known for two decades as an effective inhibitor of $\mathrm{V}$-ATPases [1], Baf has been recently recognized also as a $\mathrm{K}^{+}$ionophore with uncoupling potency on isolated mitochondria [23]. The key finding of this work was the sustained activation of respiration of intact neural cells leading to decreased cellular $\mathrm{O}_{2}$. The respiratory response to Baf developed gradually over 50-100 min, and then persisted for many hours (Fig. 1). The response became detectable at $\geq 50 \mathrm{nM}$, which is in the range of Baf concentrations found in the literature (from subnanomolar to $10 \mu \mathrm{M}[18,22])$. The ability of $\operatorname{Baf}(+)$ cells to sustain uncoupling and maintain elevated respiration for many hours without serious change in viability arises from resultant alterations in certain bioenergetic parameters. In particular, free cytosolic $\mathrm{Ca}^{2+}$ was strongly elevated as a consequence of V-ATPase inhibition, $\Delta \Psi \mathrm{m}$ was partially reduced, whereas mitochondrial $\mathrm{Ca}^{2+}$ and $\Delta \mathrm{pHm}$ were moderately decreased, thus allowing ATP production by the OxPhos. However, in the absence of glycolytic ATP supply, the total energy level in $\mathrm{Baf}(+)$ cells gradually decreased (Fig. 3c) as a consequence of increased ATP expenditure and a transient reversal of F0F1 ATP synthase activity. The latter process correlated with large continuous fluctuations of the $\Delta \Psi \mathrm{m}$ in individual mitochondria upon Baf treatment (Fig. 5, Supplementary Fig. S6, Supplementary movie), which were not observed in the cells treated with the traditional uncoupler FCCP or the $\mathrm{K}^{+}$ionophore valinomycin.

Orchestrated by Baf, gradual depolarization of the $\Delta \Psi \mathrm{m}$ developed due to progressive establishment of a new ion and energy state, which was not lethal to ${ }_{\mathrm{d}} \mathrm{PC} 12$ cells (for at least $6 \mathrm{~h}$ ). This process was accompanied by an increased proportion of mitochondria that exhibit flickering (i.e. transiently depolarized). Indeed, live imaging of the Baftreated cells demonstrated that stochastically flickering TMRM signals were colocalized with the mitochondriatargeted calcium indicator mito Case 12 only in $50-80 \%$ of mitochondria (Fig. 5a), in contrast to $90-95 \%$ in control cells. The degree of observed colocalization represents the probability of being in the polarized state for each individual mitochondrion at a given time point.

It is known that in response to $\Delta \Psi \mathrm{m}$ depolarization by FCCP, F0F1 ATP synthase reverts to an ATPase consuming ATP to restore $\Delta \Psi \mathrm{m}$, especially when glycolytic ATP supply is inhibited $[59,60]$. Our data suggest that in Baf-treated ${ }_{\mathrm{d}} \mathrm{PC} 12$ cells F0F1 ATP synthase works in both direct and reverse mode, depending on the $\Delta \Psi \mathrm{m}$ of individual mitochondria and the whole mitochondrial network. ATP synthase activity was evident, since oligomycin partially inhibited the respiratory response to Baf and induced transient ETC-mediated alkalization of the mitochondrial matrix (Fig. 4b). When the mitochondrion was depolarized by Baf, F0F1 ATP synthase switched to the reverse mode and consumed ATP for $\Delta \Psi \mathrm{m}$ restoration.

In $\operatorname{Baf}(+){ }_{d} \mathrm{PC} 12$ cells, the rate of glycolysis was increased to meet energy expenditure (Fig. 3), including the energy spent on $\Delta \Psi \mathrm{m}$ restoration by FOF1 ATP synthase. As a result, total cellular ATP levels remained practically unchanged and $\Delta \Psi \mathrm{m}$ decreased only partially. However, when complex $\mathrm{V}$ was inhibited by oligomycin and could not utilize ATP, the $\Delta \Psi \mathrm{m}$ decreased faster (Fig. 4c). If the glycolytic ATP supply was cut off, total cellular ATP decreased progressively. A further decrease in ATP upon oligomycin treatment in $\operatorname{Baf}(+)$ cells grown on galactose was somewhat surprising (Fig. 3d); it suggests that Baf-treated cells still produced ATP by OxPhos. The ability of the cells to maintain $\Delta \Psi \mathrm{m}$ flickering in galactose $(+)$ medium (data not shown) supports this conclusion. Interestingly, inhibition of the ETC complex III, but not complex V, abolished the flickering and rapidly depolarized the mitochondria (Fig. $5 \mathrm{~g}$ ). This result suggests that the activity of F0F1 ATP synthase is mediated by $\Delta \Psi \mathrm{m}$ flickering, rather than drives it.

The phenomenon of flickering mitochondrial depolarization is known. $\Delta \Psi \mathrm{m}$ may be modulated by the photoactivation of TMRM described for the tetramethylrhodamine probes [61]. It has been shown that spontaneous depolarization of individual mitochondria isolated from heart tissue and the decrease in $\Delta \Psi \mathrm{m}$ in the population of mitochondria are caused by the repeated opening of the PTP due to light-induced generation of free radicals by TMRE probe [62]. Similar results have been demonstrated for intact HeLa cells loaded with TMRM [46]. In contrast, in cultured forebrain neurons the low-amplitude spontaneous fluctuations in $\Delta \Psi \mathrm{m}$ of individual mitochondria were detected with TMRM and JC-1 probes, and were not related to light exposure [63]. The authors concluded that such $\Delta \Psi \mathrm{m}$ oscillations reflect the alternation between active and inactive states of OxPhos. In our study, we did not observe significant light-induced oscillations or a gradual decrease in TMRM signal in intact cells upon light exposure.

PTP opening has been suggested to be the mechanism involved in transient depolarizations of $\Delta \Psi \mathrm{m}[52,53]$. We showed that inhibition of PTP opening by CsA strongly increased the depolarization of mitochondria by $\mathrm{Baf}$ (Fig. 5, Supplementary Fig. S7), and did not prevent or decrease $\Delta \Psi \mathrm{m}$ flickering. Instead, the oscillations begin sooner than with Baf alone. This indicates that the initiation of flickering does not require PTP opening and that PTP opening is involved in the maintenance of mitochondrial polarization and function under conditions of impaired $\mathrm{K}^{+}, \mathrm{H}^{+}$and $\mathrm{Ca}^{2+}$ balance. It is possible that PTP opening is involved in the release of excessive osmotic pressure from the mitochondrial matrix, which is generated through $\mathrm{K}^{+}$ionophore activity of Baf. Regulation of PTP 
opening by $\mathrm{K}^{+}$influx into the matrix is discussed in [53]. Therefore, PTP opening may serve to restore the shape and function of the mitochondria. When this process is inhibited by $\mathrm{CsA}$, the $\Delta \Psi \mathrm{m}$ depolarizes more quickly. On the other hand, the fact that $\Delta \Psi \mathrm{m}$ flickering occurs in the presence of CsA, suggests that a different mechanism may also be involved in the stochastic depolarization and repolarization of mitochondria.

$\mathrm{Ca}^{2+}$ is an important regulator of mitochondrial function $[64,65]$. To transport $\mathrm{Ca}^{2+}$ into the matrix, the mitochondrial uniporter requires polarized $\Delta \Psi \mathrm{m}[66]$ and a high concentration of $\mathrm{Ca}^{2+}$ in the vicinity of the mitochondria [67]. In $\mathrm{Baf}(+)$ cells both conditions are provided: the $\Delta \Psi \mathrm{m}$ is retained by a considerable proportion of mitochondria, while cytosolic $\mathrm{Ca}^{2+}$ is strongly and steadily elevated due to the dissipation of $\mathrm{H}^{+}$gradients in the V-ATPase-regulated acidic $\mathrm{Ca}^{2+}$ stores. However, our results suggest that the effect of $\mathrm{Ca}^{2+}$ on the Baf-dependent increase in respiration is mediated by the ER, which is one of the main players in the $\mathrm{Ca}^{2+}$ turnover and a partner of the mitochondria in $\mathrm{Ca}^{2+}$ exchange $[50,51]$. We hypothesize that high cytosolic $\mathrm{Ca}^{2+}$ could randomly activate $\mathrm{Ca}^{2+}$-dependent $\mathrm{Ca}^{2+}$ release from the ER network surrounding the mitochondria. In turn, local increases in $\mathrm{Ca}^{2+}$ could activate the mitochondrial uniporter and trigger $\mathrm{Ca}^{2+}$ entry to the mitochondria. An elevation in $\mathrm{Ca}^{2+}$ transiently depolarizes $\Delta \Psi \mathrm{m}$ [63] and causes release of the mitochondrial $\mathrm{Ca}^{2+}$, which is then again buffered by the ER. This is supported by the observation that thapsigargin and BHQ, which inhibit SERCA and prevent $\mathrm{Ca}^{2+}$ crosstalk between the ER and mitochondria, abolish the respiratory effect of Baf (Fig. 6). Moreover, when SERCA is inhibited, Baf induces dramatic changes in the mitochondrial morphology and the mode of $\Delta \Psi \mathrm{m}$ flickering (Fig. 5, Supplementary Fig. S7). A similar effect on the respiratory response to Baf can be achieved with the $\mathrm{Ca}^{2+}$ chelator BAPTA, which buffers $\mathrm{Ca}^{2+}$ fluxes in the cytosol and prevents intercompartmental $\mathrm{Ca}^{2+}$ exchange. In contrast, extracellular $\mathrm{Ca}^{2+}$ does not seem to be involved in the regulation of the respiratory response to Baf.

$\mathrm{K}^{+}$balance is also important for the maintenance of $\Delta \Psi \mathrm{m}$, mitochondrial integrity and function. It is controlled by the $\mathrm{Ca}^{2+}$-dependent $\left(\mathrm{K}_{\mathrm{Ca}}^{+}\right)$and ATP-dependent $\left(\mathrm{K}_{\mathrm{ATP}}\right)$ $\mathrm{K}^{+}$channels responsible for influx, and by the $\mathrm{K}^{+} / \mathrm{H}^{+}$ exchanger which performs $\mathrm{K}^{+}$efflux from the matrix [53]. Despite the difficulties in the estimation of $\mathrm{K}^{+}$fluxes across the inner mitochondrial membrane $[68,69]$, it is considered that the $\mathrm{K}^{+}$efflux pathway exceeds influx, and the $\mathrm{K}^{+}$ concentration in the matrix is lower than in the cytoplasm [53]. An increase in matrix $\mathrm{K}^{+}$leads to depolarization and swelling of the mitochondria. This can be observed in cells treated with valinomycin, which transports $\mathrm{K}^{+}$into the matrix mimicking the activation of mitochondrial $\mathrm{K}_{\mathrm{Ca}}^{+}$and
$\mathrm{K}_{\mathrm{ATP}}^{+}$channels. Characteristic morphological changes of the mitochondria from an elongated to a more round shape suggest that $\mathrm{K}^{+}$transport by Baf may directly affect mitochondrial function and contribute to $\Delta \Psi \mathrm{m}$ depolarization and flickering by increasing matrix volume, causing swelling and physical damage to the mitochondria [53]. The dissipation of lysosomes, which are normally responsible for mitochondrial turnover [70], may also contribute to the unusual bioenergetic status of $\mathrm{Baf}(+)$ cells.

Inhibition of autophagy resulting from lysosomal dysfunction [71] does not seem to be affected by Baf uncoupling, since CMA causes a similar accumulation of LC3 II (Fig. 1f). Our data suggest that increased ROS production is caused by inhibition of V-ATPase rather than mitochondrial uncoupling (Fig. 2, Supplementary Fig. S2). However, caspase-3, the key enzyme in the apoptotic pathway, is activated by Baf to a larger degree than by CMA, suggesting that an overload of the mitochondria with $\mathrm{K}^{+}$and frequent $\Delta \Psi \mathrm{m}$ depolarization contribute to the effect of Baf on apoptosis. So far, apoptosis has been considered mostly to result from V-ATPase inhibition and lysosomal dysfunction $[15,16]$.

Our data also show that neuronal cells uncoupled by Baf, overloaded with cytosolic $\mathrm{Ca}^{2+}$ and lacking functional acidic compartments become more susceptible to excitation. Stimulation with glutamate and depolarization of $\Delta \Psi \mathrm{p}$ by high $\mathrm{K}^{+}$induce significantly stronger respiratory responses in Baf-treated cells (Fig. 7), and such amplified responses occur in the cells devoid of neurotransmission [72]. Increased susceptibility to excitatory stimulation and the evidence that increased energy demand upon excitation is not met by ATP production (Fig. 7) may have important physiological implications. Another interesting area for further investigation is the increased hypoxia in the cells uncoupled by Baf. We show here that upon Baf treatment at ambient $\mathrm{O}_{2}(200 \mu \mathrm{M}$ in extracellular medium $)$, the concentration of $\mathrm{O}_{2}$ in dense cell monolayers drops from about $150 \mu \mathrm{M}$ to $100 \mu \mathrm{M}$ and remains at this level for hours (Fig. 1). Considering the high $\mathrm{O}_{2}$ consumption by excitable tissues and limited $\mathrm{O}_{2}$ supply in solid tumours, we expect that Baf treatment may cause deep cell/tissue deoxygenation in vivo. Therefore, regulatory mechanisms modulated by hypoxia may be involved in cellular responses to Baf including apoptosis and HIF- $1 \alpha$ stabilization. So far these responses have been attributed mostly to V-ATPase inhibition by this multifunctional drug.

Acknowledgments This material is based upon work supported by the Science Foundation Ireland under Grant No. 07/IN.1/B1804. The authors thank Dr. M. Ward for assistance in the experiments with cerebellar granule neurons, Dr. C. Favre for help with FACS analysis, Prof. T. Pozzan for providing the mtAlpHi plasmid, the Department of Anatomy, UCC, for access to the confocal imaging facility and Dr. $\mathrm{J}$. Hynes for the help with manuscript correction. 
Open Access This article is distributed under the terms of the Creative Commons Attribution Noncommercial License which permits any noncommercial use, distribution, and reproduction in any medium, provided the original author(s) and source are credited.

\section{References}

1. Bowman EJ, Siebers A, Altendorf K (1988) Bafilomycins: a class of inhibitors of membrane ATPases from microorganisms, animal cells, and plant cells. Proc Natl Acad Sci U S A 85:7972-7976

2. Nishi T, Forgac M (2002) The vacuolar (H+)-ATPases - nature's most versatile proton pumps. Nat Rev 3:94-103

3. Beyenbach KW, Wieczorek H (2006) The V-type H+ ATPase: molecular structure and function, physiological roles and regulation. J Exp Biol 209:577-589

4. Shin L, Basi N, Jeremic A, Lee JS, Cho WJ, Chen Z, AbuHamdah R, Oupicky D, Jena BP (2009) Involvement of vH(+)ATPase in synaptic vesicle swelling. J Neurosci Res 88:95-101

5. Huss M, Wieczorek H (2009) Inhibitors of V-ATPases: old and new players. J Exp Biol 212:341-346

6. Werner G, Hagenmaier H, Drautz H, Baumgartner A, Zahner H (1984) Metabolic products of microorganisms. 224. Bafilomycins, a new group of macrolide antibiotics. Production, isolation, chemical structure and biological activity. J Antibiot (Tokyo) 37:110-117

7. Bowman EJ, Graham LA, Stevens TH, Bowman BJ (2004) The bafilomycin/concanamycin binding site in subunit $\mathrm{c}$ of the V-ATPases from Neurospora crassa and Saccharomyces cerevisiae. J Biol Chem 279:33131-33138

8. Bowman BJ, Bowman EJ (2002) Mutations in subunit C of the vacuolar ATPase confer resistance to bafilomycin and identify a conserved antibiotic binding site. J Biol Chem 277:3965-3972

9. Kane PM (2006) The where, when, and how of organelle acidification by the yeast vacuolar H+-ATPase. Microbiol Mol Biol Rev 70:177-191

10. Gonzalez A, Pfeiffer F, Schmid A, Schulz I (1998) Effect of intracellular $\mathrm{pH}$ on acetylcholine-induced $\mathrm{Ca} 2+$ waves in mouse pancreatic acinar cells. Am J Physiol 275:C810-C817

11. Gerasimenko JV, Lur G, Sherwood MW, Ebisui E, Tepikin AV, Mikoshiba K, Gerasimenko OV, Petersen OH (2009) Pancreatic protease activation by alcohol metabolite depends on $\mathrm{Ca} 2+$ release via acid store IP3 receptors. Proc Natl Acad Sci U S A 106:10758-10763

12. Lopez JJ, Camello-Almaraz C, Pariente JA, Salido GM, Rosado JA (2005) $\mathrm{Ca} 2+$ accumulation into acidic organelles mediated by $\mathrm{Ca} 2+-$ and vacuolar $\mathrm{H}+-\mathrm{ATPases}$ in human platelets. Biochem $\mathrm{J}$ 390:243-252

13. Petersen $\mathrm{OH}$, Tepikin AV (2008) Polarized calcium signaling in exocrine gland cells. Annu Rev Physiol 70:273-299

14. Crompton M (2000) Mitochondrial intermembrane junctional complexes and their role in cell death. J Physiol 529(Pt 1):11-21

15. Wu YC, Wu WK, Li Y, Yu L, Li ZJ, Wong CC, Li HT, Sung JJ, Cho CH (2009) Inhibition of macroautophagy by bafilomycin A1 lowers proliferation and induces apoptosis in colon cancer cells. Biochem Biophys Res Commun 382:451-456

16. Boya P, Gonzalez-Polo RA, Casares N, Perfettini JL, Dessen P, Larochette N, Metivier D, Meley D, Souquere S, Yoshimori T, Pierron G, Codogno P, Kroemer G (2005) Inhibition of macroautophagy triggers apoptosis. Mol Cell Biol 25:1025-1040

17. Yamamoto A, Tagawa Y, Yoshimori T, Moriyama Y, Masaki R, Tashiro Y (1998) Bafilomycin A1 prevents maturation of autophagic vacuoles by inhibiting fusion between autophagosomes and lysosomes in rat hepatoma cell line, H-4-II-E cells. Cell Struct Funct 23:33-42

18. Lim JH, Park JW, Kim MS, Park SK, Johnson RS, Chun YS (2006) Bafilomycin induces the p21-mediated growth inhibition of cancer cells under hypoxic conditions by expressing hypoxiainducible factor-1alpha. Mol Pharmacol 70:1856-1865

19. Semenza GL (2006) Baffled by bafilomycin: an anticancer agent that induces hypoxia-inducible factor-1alpha expression. Mol Pharmacol 70:1841-1843

20. Lim JH, Park JW, Kim SJ, Kim MS, Park SK, Johnson RS, Chun YS (2007) ATP6V0C competes with von Hippel-Lindau protein in hypoxia-inducible factor 1alpha (HIF-1alpha) binding and mediates HIF-1alpha expression by bafilomycin A1. Mol Pharmacol 71:942-948

21. Hong J, Nakano Y, Yokomakura A, Ishihara K, Kim S, Kang YS, Ohuchi K (2006) Nitric oxide production by the vacuolar-type $(\mathrm{H}+)$-ATPase inhibitors bafilomycin A1 and concanamycin A and its possible role in apoptosis in RAW 264.7 cells. J Pharmacol Exp Ther 319:672-681

22. Shacka JJ, Klocke BJ, Shibata M, Uchiyama Y, Datta G, Schmidt RE, Roth KA (2006) Bafilomycin A1 inhibits chloroquineinduced death of cerebellar granule neurons. Mol Pharmacol 69:1125-1136

23. Teplova VV, Tonshin AA, Grigoriev PA, Saris NE, SalkinojaSalonen MS (2007) Bafilomycin A1 is a potassium ionophore that impairs mitochondrial functions. $\mathrm{J}$ Bioenerg Biomembr 39:321-329

24. Dykens JA, Will Y (2007) The significance of mitochondrial toxicity testing in drug development. Drug Discov Today 12:777-785

25. Liu H, Felix R, Gurnett CA, De Waard M, Witcher DR, Campbell KP (1996) Expression and subunit interaction of voltage-dependent $\mathrm{Ca} 2+$ channels in PC12 cells. J Neurosci 16:7557-7565

26. Shafer TJ, Atchison WD (1991) Transmitter, ion channel and receptor properties of pheochromocytoma (PC12) cells: a model for neurotoxicological studies. Neurotoxicology 12:473-492

27. Reynolds EE, Melega WP, Howard BD (1982) Adenosine 5 -triphosphate independent secretion from PC12 pheochromocytoma cells. Biochemistry 21:4795-4799

28. Zhdanov AV, Ward MW, Prehn JH, Papkovsky DB (2008) Dynamics of intracellular oxygen in PC12 cells upon stimulation of neurotransmission. J Biol Chem 283:5650-5661

29. O'Riordan TC, Zhdanov AV, Ponomarev GV, Papkovsky DB (2007) Analysis of intracellular oxygen and metabolic responses of mammalian cells by time-resolved fluorometry. Anal Chem 79:9414-9419

30. Zhdanov AV, Ward MW, Taylor CT, Souslova EA, Chudakov DM, Prehn JH, Papkovsky DB (2010) Extracellular calcium depletion transiently elevates oxygen consumption in neurosecretory PC12 cells through activation of mitochondrial $\mathrm{Na}(+) / \mathrm{Ca}(2+)$ exchange. Biochim Biophys Acta 1797: $1627-1637$

31. Rizzuto R, Brini M, Pizzo P, Murgia M, Pozzan T (1995) Chimeric green fluorescent protein as a tool for visualizing subcellular organelles in living cells. Curr Biol 5:635-642

32. Rizzuto R, Nakase H, Darras B, Francke U, Fabrizi GM, Mengel T, Walsh F, Kadenbach B, DiMauro S, Schon EA (1989) A gene specifying subunit VIII of human cytochrome c oxidase is localized to chromosome 11 and is expressed in both muscle and non-muscle tissues. J Biol Chem 264:10595-10600

33. Abad MF, Di Benedetto G, Magalhaes PJ, Filippin L, Pozzan T (2004) Mitochondrial pH monitored by a new engineered green fluorescent protein mutant. J Biol Chem 279:11521-11529

34. Encinas M, Iglesias M, Liu Y, Wang H, Muhaisen A, Cena V, Gallego C, Comella JX (2000) Sequential treatment of SH-SY5Y cells with retinoic acid and brain-derived neurotrophic factor 
gives rise to fully differentiated, neurotrophic factor-dependent, human neuron-like cells. J Neurochem 75:991-1003

35. Ward MW, Rego AC, Frenguelli BG, Nicholls DG (2000) Mitochondrial membrane potential and glutamate excitotoxicity in cultured cerebellar granule cells. J Neurosci 20:7208-7219

36. Dmitriev RI, Zhdanov AV, Ponomarev GV, Yashunski DV, Papkovsky DB (2010) Intracellular oxygen-sensitive phosphorescent probes based on cell-penetrating peptides. Anal Biochem 398(1):24-33

37. Marroquin LD, Hynes J, Dykens JA, Jamieson JD, Will Y (2007) Circumventing the crabtree effect: replacing media glucose with galactose increases susceptibility of HepG2 cells to mitochondrial toxicants. Toxicol Sci 97:539-547

38. Nicholls DG (2006) Simultaneous monitoring of ionophore- and inhibitor-mediated plasma and mitochondrial membrane potential changes in cultured neurons. J Biol Chem 281:14864-14874

39. Zhdanov AV, Ogurtsov VI, Taylor CT, Papkovsky DB (2010) Monitoring of cell oxygenation and responses to metabolic stimulation by intracellular oxygen sensing technique. Integr Biol. doi:10.1039/C0IB00021C

40. Tuckerman JR, Zhao Y, Hewitson KS, Tian YM, Pugh CW, Ratcliffe PJ, Mole DR (2004) Determination and comparison of specific activity of the HIF-prolyl hydroxylases. FEBS Lett 576:145-150

41. Hynes J, O'Riordan TC, Zhdanov AV, Uray G, Will Y, Papkovsky DB (2009) In vitro analysis of cell metabolism using a long-decay $\mathrm{pH}$-sensitive lanthanide probe and extracellular acidification assay. Anal Biochem 390:21-28

42. Mizushima N, Yoshimori T (2007) How to interpret LC3 immunoblotting. Autophagy 3:542-545

43. Dmitriev RI, Okkelman IA, Abdulin RA, Shakhparonov MI, Pestov NB (2009) Nuclear transport of protein TTC4 depends on the cell cycle. Cell Tissue Res 336:521-527

44. Duffy S, MacVicar BA (1994) Potassium-dependent calcium influx in acutely isolated hippocampal astrocytes. Neuroscience 61:51-61

45. Aarts M, Iihara K, Wei WL, Xiong ZG, Arundine M, Cerwinski W, MacDonald JF, Tymianski M (2003) A key role for TRPM7 channels in anoxic neuronal death. Cell 115:863-877

46. Falchi AM, Isola R, Diana A, Putzolu M, Diaz G (2005) Characterization of depolarization and repolarization phases of mitochondrial membrane potential fluctuations induced by tetramethylrhodamine methyl ester photoactivation. FEBS J 272:1649-1659

47. Duchen MR (2000) Mitochondria and calcium: from cell signalling to cell death. J Physiol 529(Pt 1):57-68

48. Duchen MR (1992) $\mathrm{Ca}(2+)$-dependent changes in the mitochondrial energetics in single dissociated mouse sensory neurons. Biochem J 283(Pt 1):41-50

49. Gunter TE, Buntinas L, Sparagna G, Eliseev R, Gunter K (2000) Mitochondrial calcium transport: mechanisms and functions. Cell Calcium 28:285-296

50. Rizzuto R, Duchen MR, Pozzan T (2004) Flirting in little space: the ER/mitochondria Ca2+ liaison. Sci STKE 2004:re1

51. Mironov SL, Symonchuk N (2006) ER vesicles and mitochondria move and communicate at synapses. J Cell Sci 119:4926-4934

52. Jacobson J, Duchen MR (2002) Mitochondrial oxidative stress and cell death in astrocytes - requirement for stored $\mathrm{Ca} 2+$ and sustained opening of the permeability transition pore. J Cell Sci 115:1175-1188

53. Kaasik A, Safiulina D, Zharkovsky A, Veksler V (2007) Regulation of mitochondrial matrix volume. Am J Physiol Cell Physiol 292:C157-C163
54. Baysal K, Brierley GP, Novgorodov S, Jung DW (1991) Regulation of the mitochondrial $\mathrm{Na}+/ \mathrm{Ca} 2+$ antiport by matrix $\mathrm{pH}$. Arch Biochem Biophys 291:383-389

55. Thayer SA, Miller RJ (1990) Regulation of the intracellular free calcium concentration in single rat dorsal root ganglion neurones in vitro. J Physiol 425:85-115

56. Jouaville LS, Pinton P, Bastianutto C, Rutter GA, Rizzuto R (1999) Regulation of mitochondrial ATP synthesis by calcium: evidence for a long-term metabolic priming. Proc Natl Acad Sci U S A 96:13807-13812

57. Szewczyk MM, Pande J, Grover AK (2008) Caloxins: a novel class of selective plasma membrane $\mathrm{Ca} 2+$ pump inhibitors obtained using biotechnology. Pflugers Arch 456:255-266

58. Pereira CM, Oliveira CR (1997) Glutamate toxicity on a PC12 cell line involves glutathione (GSH) depletion and oxidative stress. Free Radic Biol Med 23:637-647

59. Duchen MR, McGuinness O, Brown LA, Crompton M (1993) On the involvement of a cyclosporin A sensitive mitochondrial pore in myocardial reperfusion injury. Cardiovasc Res 27:1790-1794

60. Leyssens A, Nowicky AV, Patterson L, Crompton M, Duchen MR (1996) The relationship between mitochondrial state, ATP hydrolysis, $[\mathrm{Mg} 2+] \mathrm{i}$ and $[\mathrm{Ca} 2+] \mathrm{i}$ studied in isolated rat cardiomyocytes. J Physiol 496(Pt 1):111-128

61. Tsien RY, Waggoner A (1995) Fluorophores for confocal microscopy. In: Pawley JB (ed) Handbook of biological confocal microscopy, 2nd edn. Plenum Press, New York, pp 267-280

62. Huser J, Rechenmacher CE, Blatter LA (1998) Imaging the permeability pore transition in single mitochondria. Biophys $\mathrm{J}$ 74:2129-2137

63. Buckman JF, Reynolds IJ (2001) Spontaneous changes in mitochondrial membrane potential in cultured neurons. J Neurosci 21:5054-5065

64. McCormack JG, Halestrap AP, Denton RM (1990) Role of calcium ions in regulation of mammalian intramitochondrial metabolism. Physiol Rev 70:391-425

65. Territo PR, French SA, Dunleavy MC, Evans FJ, Balaban RS (2001) Calcium activation of heart mitochondrial oxidative phosphorylation: rapid kinetics of $\mathrm{mVO}$, $\mathrm{NADH}$, and light scattering. J Biol Chem 276:2586-2599

66. Gunter KK, Gunter TE (1994) Transport of calcium by mitochondria. J Bioenerg Biomembr 26:471-485

67. Rizzuto R, Pozzan T (2006) Microdomains of intracellular Ca2+: molecular determinants and functional consequences. Physiol Rev 86:369-408

68. Garlid KD, Paucek P (2003) Mitochondrial potassium transport: the $\mathrm{K}(+)$ cycle. Biochim Biophys Acta 1606:23-41

69. Safiulina D, Veksler V, Zharkovsky A, Kaasik A (2006) Loss of mitochondrial membrane potential is associated with increase in mitochondrial volume: physiological role in neurones. J Cell Physiol 206:347-353

70. Brunk UT, Terman A (2002) The mitochondrial-lysosomal axis theory of aging: accumulation of damaged mitochondria as a result of imperfect autophagocytosis. Eur J Biochem 269:1996-2002

71. Klionsky DJ, Elazar Z, Seglen PO, Rubinsztein DC (2008) Does bafilomycin A1 block the fusion of autophagosomes with lysosomes? Autophagy 4:849-950

72. Moriyama Y, Maeda M, Futai M (1992) The role of V-ATPase in neuronal and endocrine systems. J Exp Biol 172:171-178 